\title{
RESEARCH
}

Open Access

\section{Potential biomarkers for neuroinflammation and neurodegeneration at short and long term after neonatal hypoxic-ischemic insult in rat}

Nozha Borjini ${ }^{1,2,3^{*}}$ (D, Sandra Sivilia ${ }^{3}$, Alessandro Giuliani ${ }^{3,4}$, Mercedes Fernandez ${ }^{3,4}$, Luciana Giardino ${ }^{2,3,4}$, Fabrizio Facchinetti ${ }^{1}$ and Laura Calzà $2,3,5$

\begin{abstract}
Background: Hypoxic-ischemic $(\mathrm{HI})$ encephalopathy causes life-long morbidity and premature mortality in term neonates. Therapies in addition to whole-body cooling are under development to treat the neonate at risk for $\mathrm{HI}$ encephalopathy, but are not a quickly measured serum inflammatory or neuronal biomarkers to rapidly and accurately identify brain injury in order to follow the efficacy of therapies.

Methods: In order to identify potential biomarkers for early inflammatory and neurodegenerative events after neonatal hypoxia-ischemia, both male and female Wistar rat pups at postnatal day 7 (P7) were used and had their right carotid artery permanently doubly occluded and exposed to $8 \%$ oxygen for $90 \mathrm{~min}$. Sensory and cognitive parameters were assessed by open field, rotarod, CatWalk, and Morris water maze (MWM) test. Plasma and CSF biomarkers were investigated on the acute ( $24 \mathrm{~h}$ and $72 \mathrm{~h}$ ) and chronic phase (4 weeks). Brains were assessed for gene expression analysis by quantitative RT-PCR Array.

Results: We found a delay of neurological reflex maturation in HI rats. We observed anxiolytic-like baseline behavior in males more than females following $\mathrm{HI}$ injury. $\mathrm{HI}$ rats held on the rotarod for a shorter time comparing to sham. HI injury impaired spatial learning ability on MWM test. The CatWalk assessment demonstrated a long-term deficit in gait parameters related to the hind paw. Proinflammatory biomarkers such as IL-6 in plasma and CCL2 and TNF-a in CSF showed an upregulation at $24 \mathrm{~h}$ after HI while other cytokines, such as IL-17A and CCL5, were upregulated after $72 \mathrm{~h}$ in CSF. At $24 \mathrm{~h}$ post-injury, we observed an increase of Edn1, Hif1-a, and Mmp9 mRNA levels in the ipsilateral vs the contralateral hemisphere of $\mathrm{HI}$ rats. An upregulation of genes involved with clotting and hematopoietic processes was observed $72 \mathrm{~h}$ post-injury.
\end{abstract}

Conclusions: Our work showed that, in the immature brain, the $\mathrm{HI}$ injury induced an early increased production of several proinflammatory mediators detectable in plasma and CSF, followed by tissue damage in the hypoxic hemisphere and short-term as well as long-lasting neurobehavioral deficits.

Keywords: Neonatal hypoxia-ischemia, Inflammatory biomarkers, Neurological disorders

\footnotetext{
* Correspondence: nozhaborjini@gmail.com

${ }^{1}$ Corporate Pre-clinical R\&D, Chiesi Farmaceutici S.p.A, Largo Belloli 11/A, 43122 Parma, Italy

${ }^{2}$ Health Science and Technologies Interdepartmental Center for Industrial Research, University of Bologna, Via Tolara di Sopra 41/E, l-40064 Ozzano Emilia, BO, Italy

Full list of author information is available at the end of the article
}

C The Author(s). 2019 Open Access This article is distributed under the terms of the Creative Commons Attribution 4.0 International License (http://creativecommons.org/licenses/by/4.0/), which permits unrestricted use, distribution, and reproduction in any medium, provided you give appropriate credit to the original author(s) and the source, provide a link to the Creative Commons license, and indicate if changes were made. The Creative Commons Public Domain Dedication waiver (http://creativecommons.org/publicdomain/zero/1.0/) applies to the data made available in this article, unless otherwise stated. 


\section{Background}

Despite the advances in perinatal care, hypoxic-ischemic encephalopathy remains a major clinical problem. Hypoxia-ischemia ( $\mathrm{HI}$ ) is a contributing factor to neonatal morbidity and mortality, often leading to chronic neurological disorders and disabilities, such as mental retardation, motor and behavioral developmental problems, cerebral palsy, seizure, and epilepsy [1-4]. The introduction of therapeutic hypothermia, while beneficial, still leaves many treated infants with lifelong behavioral, social, attentional, cognitive, and functional motor deficits $[5,6]$.

The susceptibility of the immature central nervous system (CNS) to $\mathrm{HI}$ is largely dependent on the temporal and regional status of critical developmental processes, as well as on the regulation of cerebral blood flow and metabolism [7]. The clinical diagnosis of neonatal HI and the assessment of disease severity mainly relies on the Sarnat score, brain CT (computed tomography) scans [8], MRI (magnetic resonance imaging), ultrasound diagnosis, and EEG (electroencephalogram) detection methods $[9,10]$. Because of the influence of the progressive disease process and other factors, the Sarnat score is subjective, and other tests have limitations and double effectiveness in premature/newborn infants. For example, after neonatal HI onset, there is a time range of $24 \mathrm{~h}$ between metabolism changes and pathological alterations leading to morphological changes in the brain. The appearance of CNS damage using neuroimaging techniques can take up to $72 \mathrm{~h}[11,12]$. Thus, the early clinical detection of blood or CSF biomarkers might have a prognostic value, also allowing a treatment monitoring, compared with MRI or CT results.

Post-ischemic neuroinflammation in the immature brain is a key pathophysiological factor in the development of HI-related injury [13-16]. However, the course of the inflammatory process has been investigated only partly in the neonatal setting $[17,18]$. Several studies have shown that neonatal HI triggers' extensive inflammatory reactions in the brain which includes activation of the innate immune system [19] and experimental studies in neonatal animals have demonstrated that inhibition of proinflammatory biomediators is neuroprotective [19-21]. The early neuroinflammatory response is associated with the production of several immune active cytokines/chemokines, microglia activation, and infiltration of peripheral immune cells [1, 10, 22, 23], which aggravates the brain injury outcomes. However, this early response that initially is harmful could be beneficial in the later stage by contributing to the restoration of tissue homeostasis [17, 24].

The identification of early noninvasive biomarkers of disease is a vital question, especially during the first period of a lifetime, since it could provide valuable, beneficial, and advanced diagnostic evidence when clinical and radiological signs are still silent. Therefore, this study aimed to identify potential biomarkers for the mechanisms underlying hypoxic-ischemic injury and the subsequent neuroinflammatory response in a validated preclinical model of $\mathrm{HI}$, focusing on the levels of inflammatory mediators in plasma and CSF, and compare their levels with the neurological disorders. We observed that cerebral hypoxic ischemia induces an early neuroinflammatory response likely contributing to delayed cellular death that extends over several days, eventually leading to the extensive brain hemisphere atrophy. Here we demonstrate that, despite the nervous system's attempt to recover in the acute phase by upregulating blood clotting and hematopoietic genes, the $\mathrm{HI}$ insult leads to short-term as well as long-lasting behavioral deficits in rats up to 4 weeks after the injury. Sex differences in the response to cerebral $\mathrm{HI}$ have also been examined in this study.

\section{Methods \\ Animals and experimental groups}

A total of 65 Wistar rat pups at postnatal day 7 (P7) of both sexes were used in this study. Rats were weaned at the age of 21 days. Animals were maintained in an animal room on a 12-h light/12-h dark cycle and at constant temperature $\left(22 \pm 2{ }^{\circ} \mathrm{C}\right)$, food and water ad libitum. All animal protocols described herein were carried out in accordance with the European Community Council Directives (86/609/EEC), approved by the intramural ethical committee for animal experimentation of Bologna University and complied with the guidelines published in the NIH Guide for the Care and Use of Laboratory. The animals were divided into three experimental groups: (a) $24 \mathrm{~h} \mathrm{HI}(n=7), 24 \mathrm{~h}$ sham $(n=6)$; (b) $72 \mathrm{~h} \mathrm{HI}(n=9), 72 \mathrm{~h}$ sham $(n=6) ;(\mathrm{c})$ P44 HI male $(n=$ 13), P44 sham male $(n=8), \mathrm{P} 44 \mathrm{HI}$ female $(n=6), \mathrm{P} 44$ sham female $(n=7)(P$, postnatal day).

\section{Inclusion and exclusion criteria}

Rat pups were randomized among litters and pups from the same litter were served for both $\mathrm{HI}$ and sham groups. Pups with weight less than $12 \mathrm{~g}$ and higher than $14 \mathrm{~g}$ were excluded from the experiment. As in a pilot study performed prior to the actual experiments, most of the rats with weight less than $12 \mathrm{~g}$ did not survive the hypoxia-ischemia procedure, while pups with weight more than $14 \mathrm{~g}$ had a variable outcome.

\section{Neonatal hypoxia-ischemia injury model}

An accepted rodent model of neonatal asphyxia is a modification of the Levine [25] done by Rice et al., [26], consisting in the combination of ischemia, achieved by unilateral occlusion of carotid artery, followed by 
exposure to hypoxia in 7-day-old rats. Indeed in rats, hypoxic seizures could be induced during the critical developmental window, P6-12, which is a period of synaptic maturation and corresponds to the age dependence of clinical hypoxia-associated neonatal seizures [27-30] and is thought to match with a human premature brain of 32-36 weeks of gestation. The most widely used animal model is the unilateral common carotid artery ligation followed by exposure to hypoxia in rats at P7. The surgery was performed on Wistar rats at P7 under a surgical microscope as described previously [26] with an introduction of some modifications. In brief, the pup was first weighed and then anesthetized with $3 \%$ isoflurane. The surgery lasted less than $5 \mathrm{~min}$. After placing the rat on a surgical heating pad at $37^{\circ} \mathrm{C}$, the skin was cleaned with $10 \%$ povidone iodide and a less than $1-\mathrm{cm}$ longitudinal midline incision of the neck was performed to expose the right common carotid artery (CCA). The fibrous sheath that wraps together both the carotid and the vagus nerve was broken and separated in order to avoid an overextension of the nerve. The CCA was permanently doubly ligated with a $5 / 0$ silk suture. After the ligation, few drops of surgical glue were used for the suture of the skin. Pups were placed above a heat mat at $37^{\circ} \mathrm{C}$ until awakening and recovering, then were returned to their dam, and were allowed to recuperate for $1.5 \mathrm{~h}$. Pups were then placed in a hypoxic chamber that contained $8 \% \mathrm{O}^{2}$ and $92 \% \mathrm{~N}^{2}$ with a constant flow of $3 \mathrm{~L} / \mathrm{min}$ for $90 \mathrm{~min}$, submerged in a water bath maintained at $32{ }^{\circ} \mathrm{C}$, which is the usual temperature to which rat pups are exposed when huddling with their mother [31, 32]. After hypoxia, all pups were returned again to their dam for recovery. Sham animals underwent the HI surgical procedures (i.e., exposure of the CCA) without artery ligation and without exposure to hypoxic conditions.

\section{Short-term neurofunctional outcome following cerebral}

HI

The examination of neurobehavioral development was performed for all rat pups from P8 to P21 after the hypoxic-ischemic insult and was carried out daily between 10 and 12 a.m. (Additional file 1: Figure S1). Body weights of rat pups were recorded daily. Pups were tested for the following neurological reflexes: (1) Righting reflex: this test is believed to be a reflection of subcortical maturation estimate, the generation of these movements from circuits in the spine connected to the supplementary motor area, the basal ganglia, and the reticular formation. The time (seconds) used by the animal to go from a supine to a prone position by placing all four paws on the surface was recorded. (2) Negative geotaxis: this test examines the sensorimotor function of neonatal rats [33]. Rat pups were placed upside down in the middle of a slope $\left(45^{\circ}\right)$ of $30 \mathrm{~cm}$. The latency to turn $180^{\circ}$ to an upward direction was recorded. From the day when the animal turns to go up, the time (seconds) it took to reach the upper side of the plane was recorded. The maximum duration of the recording was $30 \mathrm{~s}$; otherwise, the test was considered negative. (3) Sensory reflex: the ear and the eyelid of the pup were touched with a cotton swab and the first day of the ear twitch reflex and the contraction of the eyelid were recorded. (4) Auditory startle: the first day of the startle response to a clapping sound was observed. (5) Crossed extensor reflex: the left hind paw was pinched and the possible extension of the right paw was recorded. (6) Limb placing: the back of the forepaw and hind paw was touched with the edge of the bench while the animal is suspended, and the first day of lifting and placing the paws on the table was noted. (7) Limb grasp: the forelimbs were touched with a thin rod, and the first day of grasping onto the rod was recorded. (8) Gait: the animals are placed at the center of a white plexiglass circle $(\varnothing=13 \mathrm{~cm})$. Register the day when they start to move out of the circle with both front paws, estimate the time (seconds) that the animal uses to exit out of the circle. In the case in which the animal does not leave the circle within $30 \mathrm{~s}$, the test is considered negative. In order to assess the development of neurological reflexes, rats are given a score to the corresponding time (seconds). The higher score indicates greater capacity for the development of neurological reflexes.

\section{Long-term neurofunctional outcome after $\mathrm{HI}$ insult}

The assessment of long-term neurofunctional handicap was performed in sham and $\mathrm{HI}$ groups 3 weeks after the insult (P28). These tasks consisted of the open-field, rotarod, Catwalk, and Morris water maze (MWM) behavior tests (Additional file 1: Figure S1).

\section{Open field}

Animals were observed for locomotor behavior in an open field. Pups were placed in an open field consisting of a $46 \times 46-\mathrm{cm}$ plastic chamber with $41-\mathrm{cm}$ high walls around, with a dark gray floor virtually divided into 16 fields by the software. Rats were placed individually in the center of the chamber always facing the same direction, and the latency to leave this first square was recorded. The following parameters were measured using AnyMaze Video tracking software (AnyMaze, Stoelting, Wood Dale, IL, USA): distance traveled, rearing, grooming, and ambulation frequency. Speed was calculated from the ambulatory time and the total traveled distance. Animals were video-recorded for $10 \mathrm{~min}$ [34]. 


\section{Rotarod}

The rotarod test (LE 8500 RotaRod: 2Biological Instruments, Varese, Italy) consists on a 2-day test. Animals were exposed to one habituation session during $3 \mathrm{~min}$ in the apparatus on slow velocity $(20 \mathrm{rpm})$. In the test session, $24 \mathrm{~h}$ later, the animal's motor ability was evaluated. The rotarod test was performed by placing rats on rotating drums and measuring the time each animal maintained its balance on the rod. The acceleration rate of the rotarod was from 16 to $40 \mathrm{rpm}$ over a 6-min period. The variables recorded were the latency of the first downfall, the number of falls (maximum of three), and the time of permanence in the apparatus $[35,36]$.

\section{CatWalk}

Cortical function was analyzed by CatWalk (Noldus Information Technology, Wageningen, The Netherlands), a quantitative gait analysis system. Each rat ran across a glass walkway transversely, three complete runs were recorded using a camera positioned below, and the average was calculated. If an animal failed to complete a run within $5 \mathrm{~s}$, walked backwards, or reared during the run, the process was repeated. The experiment was performed in the dark; the glass walkway was illuminated with beams of light, thereby allowing the animals' paws to reflect light as they touched the glass floor. Each paw was labeled on the recorded video in order to calculate paw-related parameters. The gait-related parameters measured using the CatWalk system were the following: maximum contact area: the maximum area of a paw that comes into contact with the glass plate; stand: stance phase is the duration in seconds of contact of a paw with the glass plate and swing speed is the speed (distance unit/second) of the paw during swing. The formula of swing speed is swing (seconds) phase which is the duration in seconds of no contact of a paw with the glass plate. For the stride length which is the distance (in distance units) between successive placements of the same paw, the calculation of stride length is based on the Xcoordinates of the center of the paw print of two consecutive placements of the same paw during max contact and taking into account Pythagoras' theorem [37].

\section{Morris water maze}

Three weeks after HI lesion, the spatial memory performance was evaluated using an MWM $(180 \mathrm{~cm}$ diameter, $45 \mathrm{~cm}$ high) virtually divided in four equal imaginary quadrants by the AnyMaze software. The water of the pool was made opaque by using non-toxic gray tempera paint. The water level was $1 \mathrm{~cm}$ above the platform made of transparent plexiglass $(10 \mathrm{~cm}$ diameter $)$. The training consisted of a swim followed by a $30 \mathrm{~s}$ platform sit. The escape latency to find the platform was measured for individual animals on each day. The experimenter guided rats that did not find the platform within $120 \mathrm{~s}$ to it. To assess long-term memory, $24 \mathrm{~h}$ after the final trial, the platform was removed from the maze and a 2-min free swim will be conducted, and the time (seconds) spent during the first $20 \mathrm{~s}$ and the entire swim in the quadrant formerly occupied by the platform will be recorded [38].

\section{CSF and plasma biomarker analysis}

The method of CSF sampling was adapted from the method of Liu et al., [39, 40]. Briefly, the rat pup was anesthetized by isoflurane inhalation (isofluorane 4\%) (Gas Anesthesia System-21100, Ugo Basile, Varese, Italy) and fixed by one investigator with the head positioned at a $90^{\circ}$ angle. A sagittal incision of the skin was made below the occiput, and the subcutaneous tissue and neck muscles through the midline were separated and held apart using a microretractor. The dura mater of the cisterna magna was then penetrated by an $8-\mathrm{cm}$-long glass capillary, which had a narrowed tip with an inner diameter of about $0.3 \mathrm{~mm}$ so that the CSF flowed into the capillary. After collection, each sample was centrifuged at $2000 \times g$ for $10 \mathrm{~min}$ at $4{ }^{\circ} \mathrm{C}$, and the supernatant was aliquoted and stored at $-80^{\circ} \mathrm{C}$ for biochemical assays. Blood was collected from the abdominal aorta in EDTAK2 Vacutainer tubes and centrifuged at $3000 \times g$ for 10 min at $4{ }^{\circ} \mathrm{C}$, and the plasma was collected, aliquoted, and stored at $-80^{\circ} \mathrm{C}$ until used.

Proteins known to play key roles in neuroinflammation pathways were selected. For this purpose, Bio-Plex Pro $^{\text {Ts }}$ Rat Cytokine 24-plex Assay (Bio-Rad; Milano, Italy) was used. The kit included EPO, G-CSF (CSF3), GMCSF (CSF2), GRO/KC, IFN- $\gamma$, IL-1 $\alpha$, IL-1 $\beta$, IL-2, IL-4, IL-5, IL-6, IL-7, IL-10, IL-12p70, IL-13, IL-17A, IL-18, M-CSF (CSF1), MCP-1 (CCL2), MIP-1 $\alpha$ (CCL3), MIP$3 \alpha$ (CCL20), RANTES (CCL5), TNF- $\alpha$, and VEGF. The simultaneous quantification of the different proteins in CSF and plasma was performed using xMAP technology and a MAGPIX Luminex platform. This technology makes use of different populations of color-coded beads conjugated with monoclonal antibodies specific to a particular protein, thus allowing simultaneous capture and detection of specific analytes from a sample. All the beads from each set are read off, which further validates the results. Using this process, xMAP Technology allows multiplexing of up to 50 unique bioassays within a single sample, both rapidly and precisely [41, 42]. In brief, after the incubation of a specific monoclonal antibody conjugated bead population with $50 \mu \mathrm{l}$ of CSF/plasma samples for $1 \mathrm{~h}$ at RT, washed beads were incubated with a detection antibody solution at RT for $30 \mathrm{~min}$, then with the streptavidin-phycoerythrin conjugated solution (RT, $10 \mathrm{~min})$. After washing, beads were resuspended in the assay buffer, shaken for $1 \mathrm{~min}$, and then read on the 
MAGPIX instrument. The results were analyzed with xPONENT $4.2^{\circ}$ software and expressed as picograms per milliliter.

\section{Gene expression analysis by quantitative RT-PCR Array} The total RNA was prepared from the brain using QIAzol Reagent, cleaned with RNeasy Mini kit (Qiagen; MilanoItaly), and eluted in RNase free water. The purity and concentration of RNA were evaluated by spectrophotometry using NanoDrop ND-2000 (ThermoScientific, Milano, Italy). Complementary DNA (cDNA) synthesis was performed using $\mathrm{RT}^{2}$ First Strand kit (Qiagen) following the manufacturer's instructions. The expression analysis of 84 genes associated with hypoxia was carried out with the $\mathrm{RT}^{2}$ Profiler $^{\text {ra }}$ PCR Array Rat Hypoxia Signaling Pathway (PARN-032Z, Qiagen) according to the manufacturer's guidelines in 96-well plates with a CFX96 Touch $^{\text {Tw }}$ RealTime PCR Detection System (Bio-Rad). The raw data obtained was uploaded into GeneGlobe for analysis. Relative quantification of messenger RNA (mRNA) expression was calculated using the comparative cycle threshold (CT) method and expressed as $\log 2$-fold change of expression. The fold change $\left(2^{-\Delta \Delta C t}\right)$ is the normalized gene expression $\left(2^{-\Delta C t}\right)$ in the test sample which is the ipsilateral hemisphere divided by the normalized gene expression $\left(2^{-\Delta C t}\right)$ in the control sample (the contralateral hemisphere).

\section{Statistical analysis}

Results in the appearance of physical and neurological reflexes as well as body weights were compared with Student's $t$ test. Statistical differences between groups for each outcome measured were analyzed using oneway ANOVA or two-way ANOVA followed by Tukey's post hoc. All the data were expressed as mean \pm SEM and significance was set at $P \leq 0.05$. All statistical analyses were performed using GraphPad Prism 7.0 (GraphPad Software). For the normalization of gene expression on the $\mathrm{RT}^{2}$ PCR Profiler Array, data were normalized to five housekeeping genes included in the kit. The CT was determined for each sample and normalized to the average CT of the five housekeeping genes. A comparative CT method was used to calculate relative gene expression. Data are represented as log2-fold change relative to control. The $P$ values were calculated on the basis of a Student's $t$ test of the replicate $2^{-\Delta C t}$ values for each gene in the control group and treatment groups, and $P$ values less than 0.05 were considered significant.

\section{Results}

Three rats died during different steps of the experiment (mortality rate, $4.6 \%$ ). Animals were weighed every day of life, and all along the experiment, there were no significant differences in body weight, neither between sham and HI groups nor between $\mathrm{HI}$ males and females
(Fig. 1a). HI induced brain edema in the acute phase 24 and $72 \mathrm{~h}$ after unilateral ligation of the right carotid artery and hypoxia for $90 \mathrm{~min}$ in neonatal rat and tissue loss in the chronic phase, i.e., after 4 weeks (Fig. 1b).

\section{Delay of neurological reflexes maturation in $\mathrm{HI}$ rats}

As it is shown in Fig. 1c, the right eye opening day was delayed in hypoxic-ischemic animals $(P<0.0001)$. In addition, several neurological reflexes, such as negative geotaxis, ear twitch reflex, auditory startle, hindlimb grasp, and gait reflex $(P=0.0042 ; P=0.0025, P=0.0032$; $P=0.0127 ; P=0.0008$, respectively) appeared significantly later compared to normal pups. HI injury caused not only the delay in the appearance of some reflexes but animals performed certain tasks in significantly longer times (data not shown).

\section{Anxiolytic-like baseline behavior in males following $\mathrm{HI}$ injury}

The open-field test was performed in rats at P28 as a measure of anxiety response to novelty. There was no significant difference between $\mathrm{HI}$ and sham rats concerning the number of crossing, general activity, and movement pattern (Fig. 2a). HI males more than female rats spend significantly more time exploring the unprotected center area demonstrate anxiolytic-like baseline behavior ( $P=0.0005 ; P=0.0007$, respectively) and less time in contact with the walls (thigmotaxis) comparing to sham rats (Fig. 2b, d). There was no significant difference in the time spent with grooming activity or in the number of fecal boluses at any time point between the different groups (data not shown) while a significant difference was observed in HI male and female rats in the number of rearing all along the test duration comparing to sham animals $(P<0.0001 ; P<0.0001$, respectively) as it is shown in Fig. 2c. Among HI rats, there was a significant difference between sexes $(P=0.0052)$.

\section{Cerebellar dysfunction following $\mathrm{HI}$ injury}

The rotarod test was performed in rats at P28 to evaluate cerebellum-dependent sensory-motor coordination. During the habituation session, HI (Fig. 3a) rats were not able to stay on the rod compared to sham when the rod was rotated at a steady rate of $20 \mathrm{rmp}(P<0.0001$, $P<0.0001$; HI female vs sham female and HI male vs sham male, respectively). During the test session (Fig. 3b), $24 \mathrm{~h}$ later, HI female and male rats were held on the rotarod for a significantly shorter time comparing to sham $(P<0.0001, P<0.0001)$. Among $\mathrm{HI}$ rats, there were no significant differences between sexes.

\section{$\mathrm{HI}$ injury impairs spatial learning ability}

In order to determine the effect of $\mathrm{HI}$ injury on cognitive capacities, 28-day-old rats were trained in the spatial 


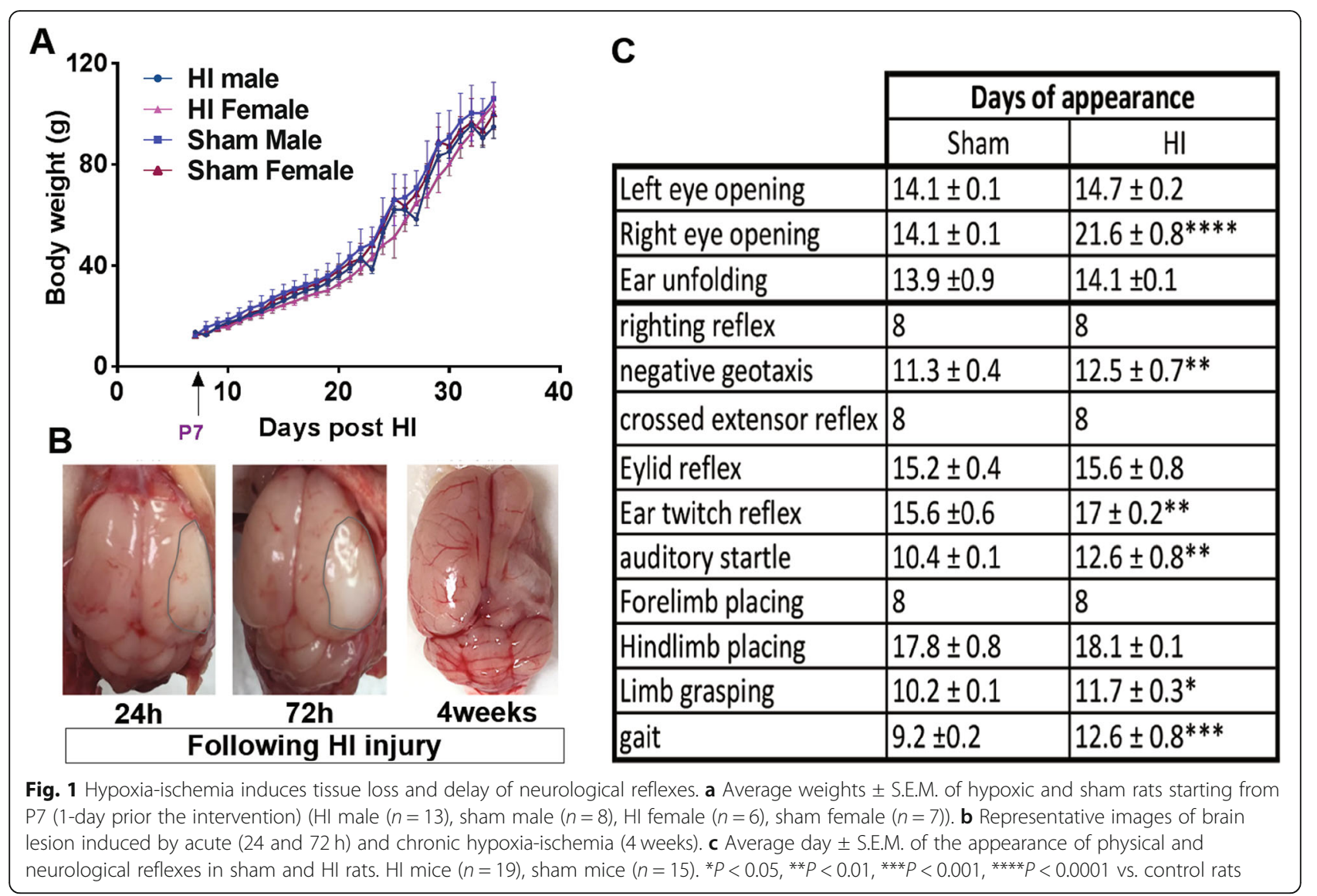

version of the MWM. A two-way ANOVA test revealed significant differences in the escape latency of the second between the experimental groups $(P<0.0001$, $P<0.0001$; HI female vs sham female and $\mathrm{HI}$ male vs sham male, respectively) during the training period (Fig. 3c). As shown in Fig. 3d, the cumulative distance to the platform to 4 days and even on the test day was shorter in sham-operated rats when compared with the $\mathrm{HI}$ groups, indicating that $\mathrm{HI}$ impaired the memory performance in the injured animals. Among HI rats, no significant differences between females and males were detected.

\section{$\mathrm{HI}$ injury impairs locomotion coordination and gait}

The CatWalk assessment of motor function post $\mathrm{HI}$ in the rat demonstrates a long-term deficit in behavioral parameters related to the hind paw, in particular for the maximum contact area and stand and swing speed of the four limbs (Fig. 4). This test was performed in rats at P28. HI males have higher run duration than sham, $(P<0.001)$. Additional post Tukey analysis showed that $\mathrm{HI}$ animals have significant impairment in the maximum contact area of their right fore (RF), right hind (RH), left fore (LF), and especially the left hind (LH) paws comparing to sham rats (Fig. $4 \mathrm{~b})(P<0.05, P<0.01, P<0.001$, or
$P<0.0001$ ). Figure $4 \mathrm{c}$ indicates that the duration in seconds of contact of a paw with the glass plate of HI rats comparing with sham showed an increase in stand duration $(P<0.05, P<0.01$, or $P<0.001)$. In $\mathrm{HI}$ animals, the swing speeds (Fig. 4d) of their four limbs were all decreased compared to those of the rats in the sham group $(P<0.05$ or $P<0.01)$. Overall, $\mathrm{HI}$-induced sensorimotor function deficits in $\mathrm{HI}$ rats and $\mathrm{HI}$ males were worse than $\mathrm{HI}$ females.

\section{Alteration of the protein expression profile during the acute phase of $\mathrm{HI}$}

Twenty-four cytokines and chemokines were simultaneously quantified in plasma and CSF samples at the different investigated time points, in the acute phase, e.g., 24 and $72 \mathrm{~h}$ and in the chronic phase, e.g., 4 weeks. Several proinflammatory biomarkers such as CCL2, CCL3, and IL-6 $(P=0.0184, P=0.0337$, and $P=0.0020$, respectively) in plasma (Fig. $5 \mathrm{a}, \mathrm{c}$, and $\mathrm{f}$ and Additional file 3: Table S1) and TNF- $\alpha$ and CCL2 $(P=0.0412 ; P<0.0001$, respectively) in CSF (Fig. $5 \mathrm{~g}, \mathrm{~b}$ and Additional file 4: Table S2) were significantly regulated as soon as $24 \mathrm{~h}$ after $\mathrm{HI}$ while the major part of the biomarkers investigated was regulated $72 \mathrm{~h}$ after $\mathrm{HI}$ such as CSF1, IFN- $\gamma$, and CCL5 $(P=0.0483 ; P=0.0193$; ns, 

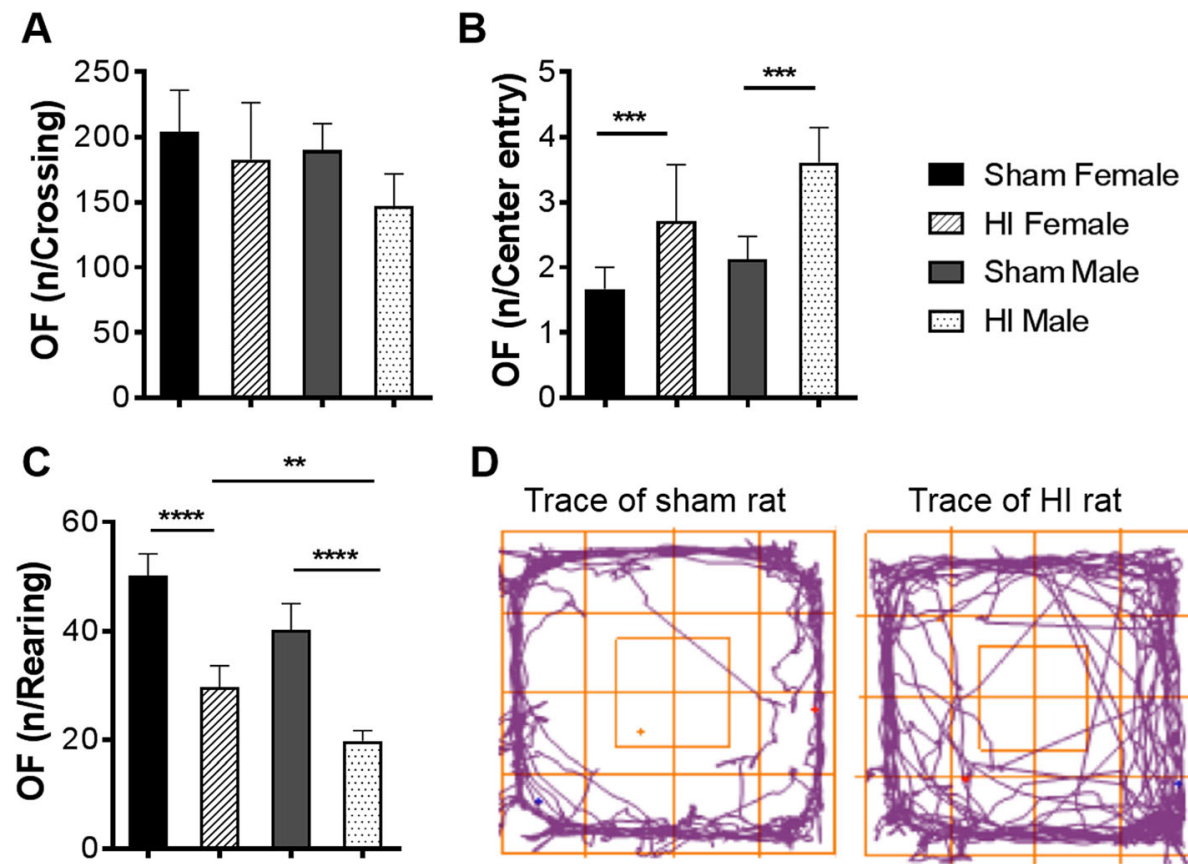

D

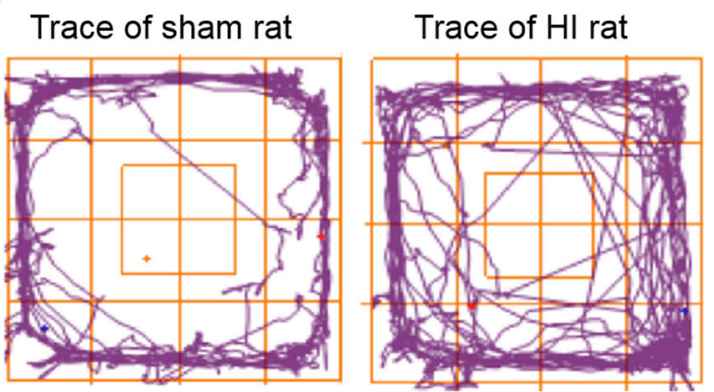

Fig. 2 Effect of neonatal HI on open-field performance in sham and HI rats at P28. a Number of crossing. b Frequency of entry to the center. $\mathbf{c}$ Number of rearing. Graphs show average values \pm S.E.M. $\mathbf{d}$ Representative traces of sham and $\mathrm{HI}$ rat movement during the open-field test. Statistical analysis: two-way ANOVA and multiple comparison test $\left({ }^{*} P<0.01,{ }^{* *} P<0.001,{ }^{* * *} P<0.0001\right)$. Test duration: 10 min. $N=13$ male HI, 6 female $\mathrm{HI}, 8$ male sham, 7 female sham. P, postnatal

respectively) in plasma (Fig. 5b, e, and $\mathrm{i}$ and Additional file 3: Table S1) and CCL5, CSF1, VEGF, and IL17A $(P<0.0001 ; P=0.0003 ; P=0.0024, P<0.0001$, respectively) in CSF (Fig. 6a, c, e, and h and Additional file 4: Table S2).

During the chronic phase, 4 weeks after the injury, in plasma, only TNF- $\alpha$ and IFN- $\gamma(P<0.0001 ; P=0.0047$, respectively) were significantly upregulated at this time point in male $\mathrm{HI}$ compared to sham male (Fig. $5 \mathrm{~d}$, e and Additional file 3: Table S1) and only TNF- $\alpha$ $(P=0.0009)$ was significantly increased on female $\mathrm{HI}$ compared to the female sham group (Fig. $5 \mathrm{~d}$ and Additional file 3: Table S1). In CSF, only CCL5 and TNF- $\alpha$ $(P=0.0164 ; P=0.0012$, respectively) were significantly upregulated at this time point in male HI compared to sham male (Fig. 6a, g and Additional file 4: Table S2) and only TNF- $\alpha(P=0.0164)$ was significantly increased on female HI compared to the female sham group (Fig. 6g and Additional file 4: Table S2). The rest of the measurable biomarkers of the panel, at the chronic phase in plasma and CSF HI rats, showed no significant change neither between $\mathrm{HI}$ and sham males nor between $\mathrm{HI}$ and sham females. Among HI rats, there were no significant differences between sexes (Figs. 5 and 6 and Additional file 3: Table S1 and Additional file 4: Table S2).
No significant changes were observed for the rest of the panel compared to the sham group. The biomarkers G-CSF (CSF3), GM-CSF (CSF2), IL-1 $\alpha$, IL-7, IL-10, and IL-12p70 were not detected at any of the time points analyzed in the CSF in our experimental conditions.

\section{Altered gene expression profile induced by $\mathrm{HI}$}

The mRNA expression of genes directly involved in the response to hypoxia and oxidative stress, apoptosis, signal transduction, and protein metabolism, as well as genes involved in cell growth and metabolism, extracellular matrix, and adhesion molecules, was studied in the ipsilateral vs the contralateral hemisphere of both HI and sham animals by real-time PCR. The complete list of investigated genes is presented in Fig. 7e. At $24 \mathrm{~h}$ post-injury, Edn1, Hif1- $\alpha$, and Mmp9 were highly upregulated in the ipsilateral vs the contralateral hemisphere of hypoxic-ischemic rats (447.65 $\log 2$-fold, 169.20 log2-fold change, $103.67 \log 2$-fold change, respectively). LOC367198 was downregulated (-30.38 $\log 2$-fold change) (Fig. 7a, e and Additional file 2: Figure S2A, E). At $72 \mathrm{~h}$ post-injury, Car9, Epo, Hnf4a, F10, and Cdkn2a were highly upregulated in the ipsilateral vs the contralateral hemisphere of hypoxic-ischemic rats (106.97 log2-fold change, $182.27 \log 2$-fold change, $110.43 \log 2$ fold change, $309.23 \log 2$-fold change, and $32.64 \log 2-$ 


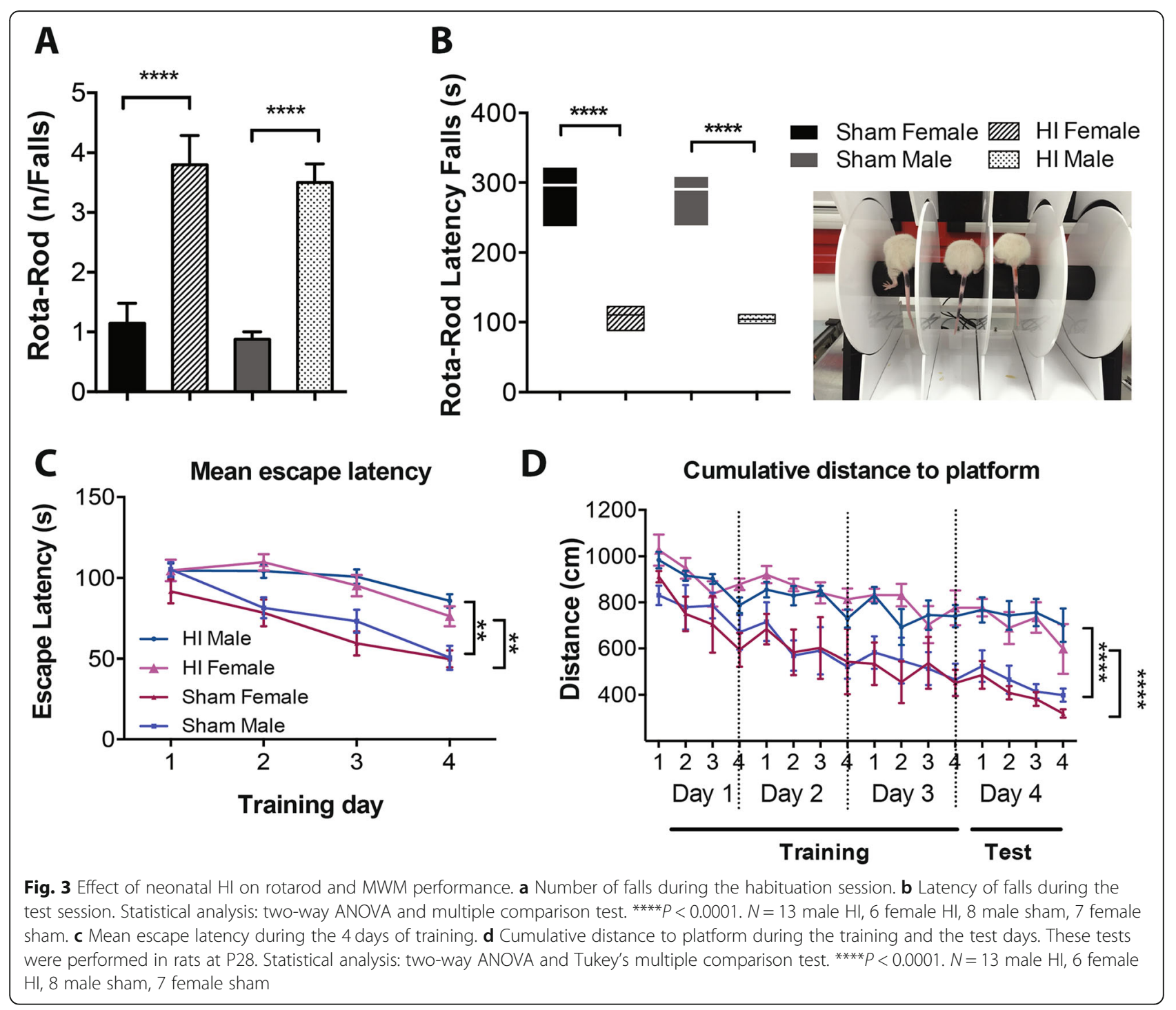

fold change, respectively) (Fig. 7b, e and Additional file 2: Figure S2B, E). Most of the genes were upregulated in the ipsilateral vs the contralateral hemisphere of $\mathrm{HI}$ rats (both sexes) during the chronic phase (4 weeks after the injury), in particular, Egr-1. Ctsa was downregulated ($2.35 \log 2$-fold change) for $\mathrm{HI}$ male rats (Fig. 7c, e and Additional file 2: Figure S2C, E) and Edn1 (- $17.63 \log 2$-fold change) for $\mathrm{HI}$ female rats (Fig. $7 \mathrm{~d}$, e and Additional file 2: Figure S2D, E).

\section{Discussion}

The main goal of the present study was to investigate potential plasma and CSF biomarkers of brain damage after acute and chronic $\mathrm{HI}$, and also according to the neurological maturation and development of complex behaviors. Our results point out the potential critical role of inflammatory biomarkers to enable early identification of infants at risk of long-term injury but also for monitoring treatment efficacy that can produce significant and lifelong improvements on the quality of life for neonates.

HI was induced at P7 in both female and male Wistar rats. We have shown that, in both female and male rats, HI leads to tissue damage and atrophy of the hypoxic hemisphere that is accompanied by short-term, retarded neurobehavioral development (delayed appearance and worse performance of some neurological reflexes), as well as long-lasting deficits in complex behaviors (retarded development of motor coordination and impaired learning in spatial tasks).

We first characterized the neurological and behavioral maturation of $\mathrm{HI}$ compared to sham-operated rats. $\mathrm{Al}$ though it was previously reported that in this HI model, pups can suffer of diminished weight gain during the development and thus needing artificial feeding [43, 44], in our HI rat model, we did not observe any significant 


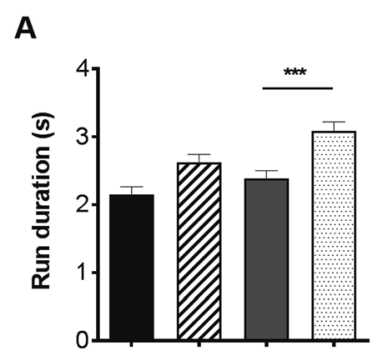

B
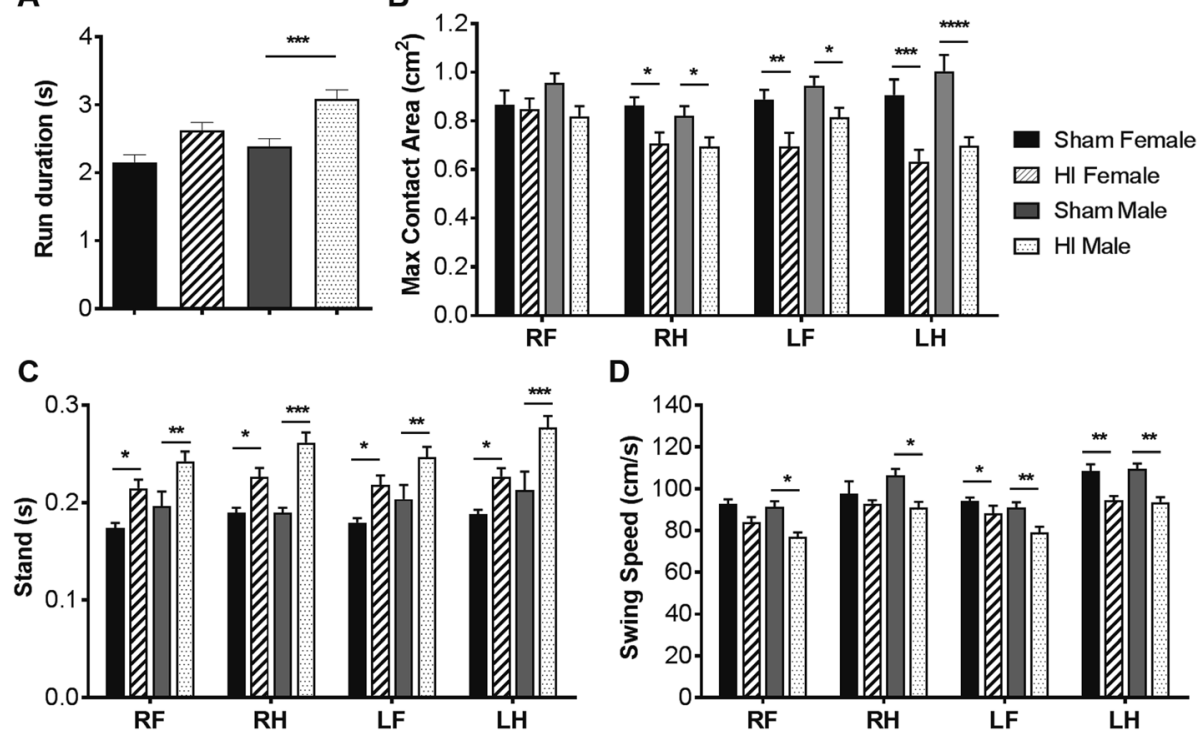

D

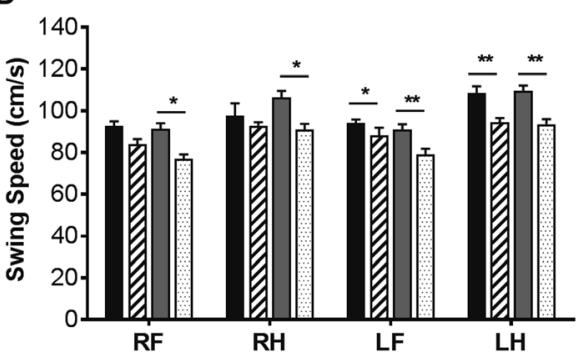

Fig. 4 Motor function was assessed with a CatWalk gait analysis system at P28. a Run duration, $\mathbf{b}$ maximum contact area, and $\mathbf{c}$ stand and $\mathbf{d}$ swing speed. Statistical analysis: two-way ANOVA and Tukey's multiple comparison test $\left({ }^{*} P<0.05,{ }^{* *} P<0.01,{ }^{* * *} P<0.001,{ }^{* * * *} P<0.0001\right)$. N $=13$ male $\mathrm{HI}, 6$ female $\mathrm{HI}, 8$ male sham, 7 female sham. RF, right fore; RH, right hind; LF, left fore; LH, left hind limbs

difference in the somatic development. This is probably because we pre-established the study design stringent inclusion/exclusion criteria related to the bodyweight of the pups, and this could have improved the health status, survival, and experimental variability. Our results show that $\mathrm{HI}$ animals perform worse in negative geotaxis, ear twitch, auditory startle, hindlimb grasp, and gait test as measured by the reflex times, independent of sex. This is in line with previous studies showing that HI in rodent models affects the short-term outcome of righting, geotaxis reflexes as measured 1 and $24 \mathrm{~h}$ after the insult $[30,43,45]$. We extended our observations to 4 weeks post-injury and found that some neurological reflexes are impaired also in the chronic phase.

In order to assess the long-term neurofunctional consequences following neonatal $\mathrm{HI}$, several complex behaviors have been examined in 6-week-old animals, including sensorimotor integration in accelerating rotarod, spontaneous locomotion in open field, gait in CatWalk apparatus, and spatial learning in Morris water maze.

Concerning the locomotor behavior in an open field, both hyper- and hypoactivity have been described following $\mathrm{HI}$ insults. In accordance with other reports $[34,45,46]$, we did not see any significant differences concerning the number of crossing, general activity, and movement patterns in the time spent with grooming activity or in the number of fecal boluses at any time point between the different groups. However, a significant decrement was observed in $\mathrm{HI}$ rats (both males and females) in the number of rearing in comparison to sham animals. In adult rats ( 15 weeks old), hypoactivity has been described [47]. We observed also that both HI female and male rats spent more time in the center and less time at walls and in corners than sham rats, which is exactly the opposite of the natural reflex of the pups, who quickly find the wall where they feel safer.

In order to determine the effect of $\mathrm{HI}$ insult on cognitive capacities, particularly in the spatial learning and memory, the MWM test was used. The following parameters were considered: the escape latency to reach the platform; a revealing parameter of working memory, which is tested during the training phase; and the reference memory components recorded on the probe phase (fifth day) of the task, including the cumulative distance to platform. Our data clearly indicates that both learning and memory performance are affected in the injured animals. Our findings are in agreement with results from De Paula et al. and Goren et al., showing that the MWM test was sensitive to brain damage in neonatal HI rats $[48,49]$.

The CatWalk assessment of gait demonstrates the long-term deficit in several parameters related to the hind paws of $\mathrm{HI}$ compared to sham-operated rats. In particular, $\mathrm{HI}$ animals showed a significant impairment in the maximum contact area of their four limbs, especially the left hind paws, in comparing to sham rats. In addition, the duration of contact of a paw with the glass plate showed an increase in stand duration in HI rats compared with sham. In addition, the swing speed of all four limbs was decreased in HI rats. Overall, HI males performed worse than $\mathrm{HI}$ females, a finding in line with 


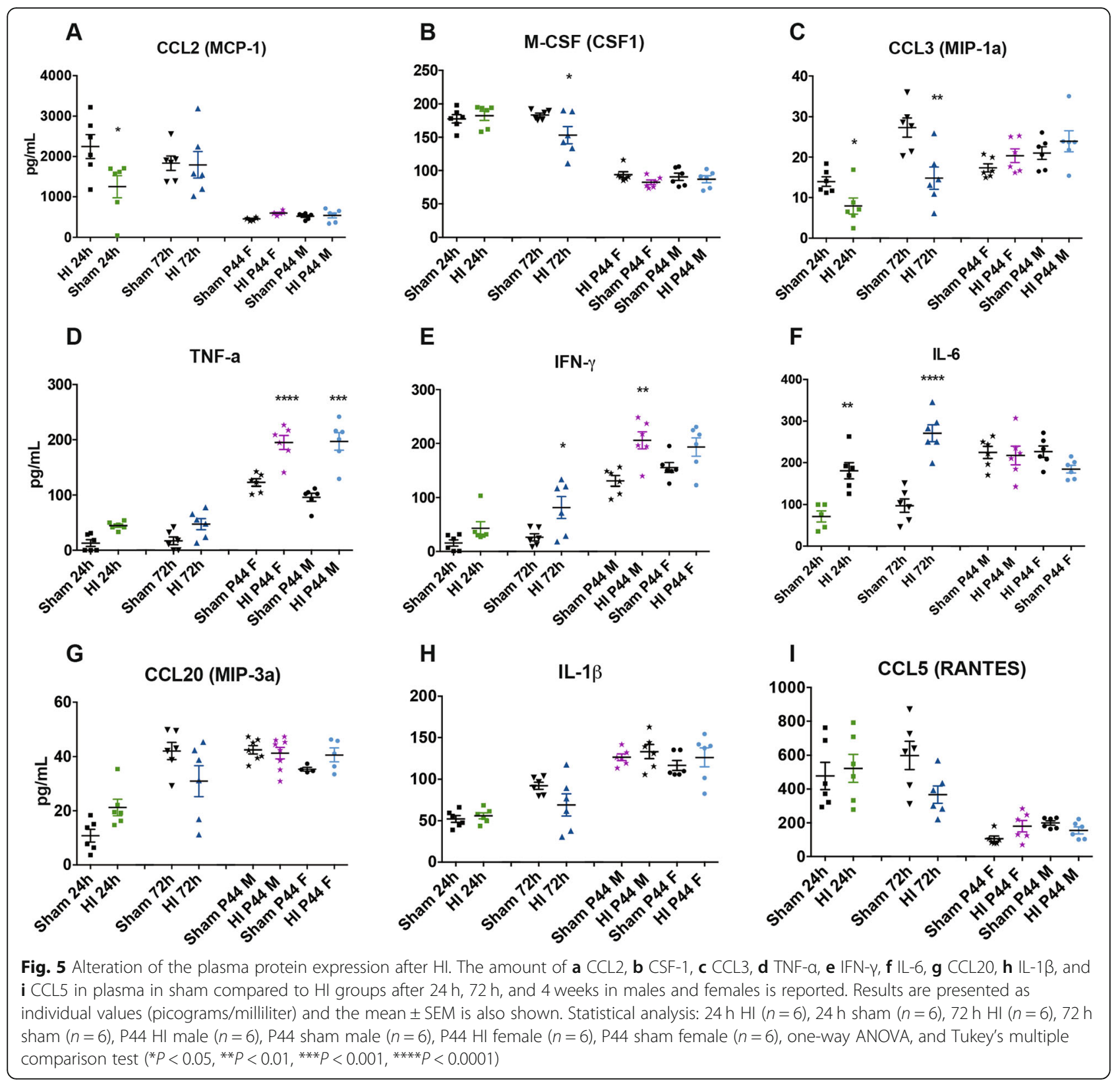

the notion that important cerebral palsy and related developmental disorders are more common in males than in females [50]. Data from neonatal rodents subjected to hypoxia-ischemia also demonstrate the involvement of different death pathways between males and females. For instance, the knockout of the gene for poly (ADP-ribose) polymerase (PARP-1), a major step in the cascade of injury, protected male but not female mouse pups from hypoxic-ischemic injury [51].

Interestingly, $\mathrm{HI}$ insult does induce sensorimotor functional deficits in some parameters while in others, we observe a slight recovery and no significant difference between $\mathrm{HI}$ and sham group. This could be explained by the extraordinary plasticity of the neonatal brain, allowing compensatory mechanisms such as the shift of motor coordination control from a damaged brain area to an unharmed one [34, 49, 52].

We then investigated several potential biomarkers of brain damage in plasma and CSF, considering that this model includes systemic hypoxia and as such, much of the increases in cytokines in the blood could well be coming from systemic organ damage [2, 53, 54]. Several studies have shown that neonatal HI triggers widespread inflammatory reactions in the brain including the activation of the innate immune system $[55,56]$. We focused on related cytokines and chemokines, using a Luminex- 


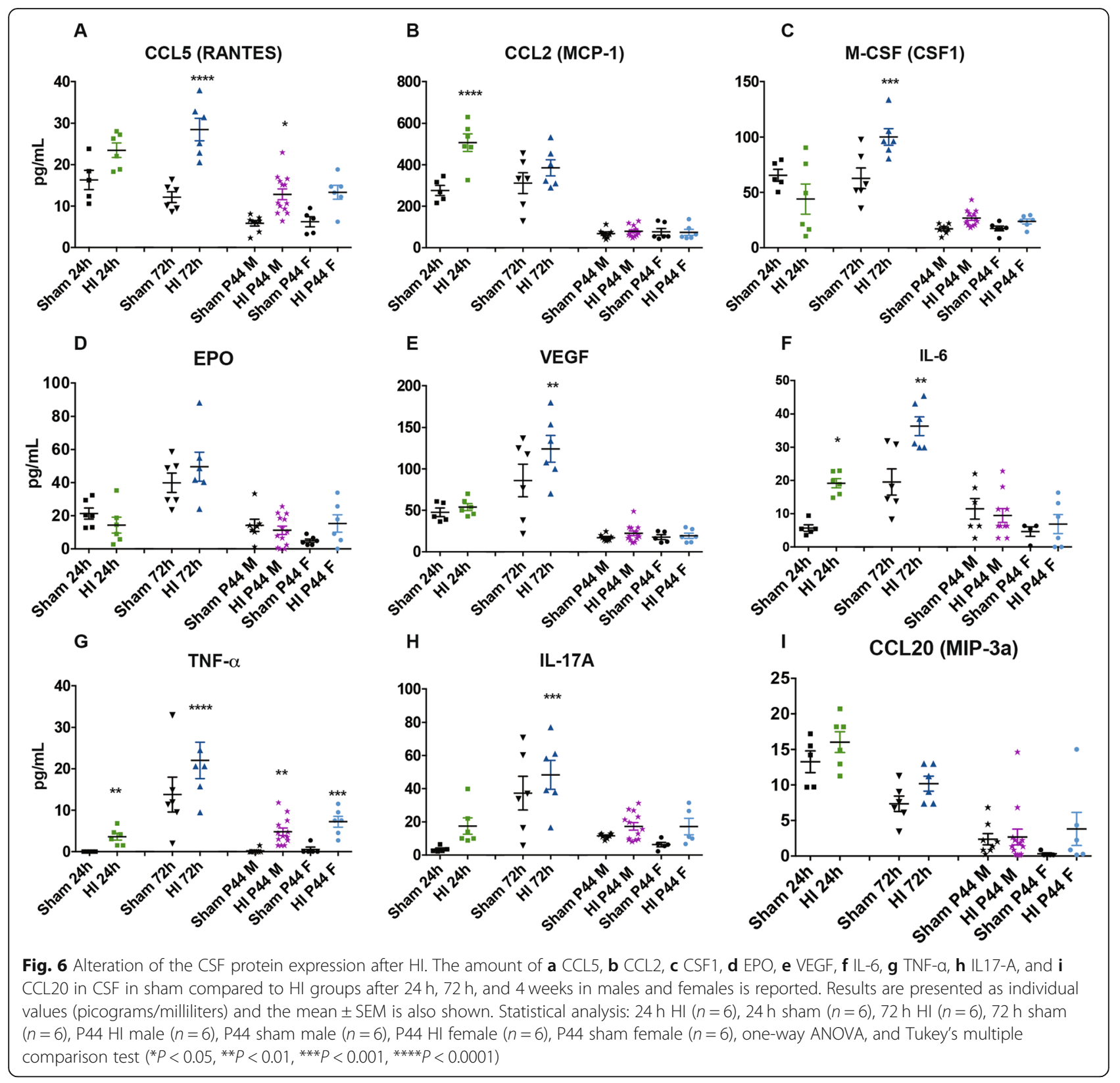

based multiparametric assay. Our results demonstrate that an early regulation of most inflammatory biomarkers was observed as soon as 24 and $72 \mathrm{~h}$, after $\mathrm{HI}$, while no significant change neither between $\mathrm{HI}$ and sham males nor between HI and sham females was observed at the chronic phase, in both plasma and CSF. Some proinflammatory biomarkers such as CCL3, CCL2, and IL- 6 in plasma and CSF regulated as soon as $24 \mathrm{~h}$ after $\mathrm{HI}$ while most of the biomarkers measured, such as CSF1, IFN- $\gamma$, CCL5, were regulated $72 \mathrm{~h}$ after HI. Notably, it has been shown that in term neonates, the CSF levels of IL-6 after perinatal asphyxia correlates to the severity of early neonatal $\mathrm{HI}$ and to late neurological outcome $[15,56-60]$. In our model, we do observe an upregulation of IL-6 at 24 and $72 \mathrm{~h}$ in plasma and CSF. Both CCL2 and CCL3 are necessary for recruiting monocyte to the injury site, where they play an important role in CNS plasticity and repair [61, 62]. It was recently described that CCL2 and its receptor CCR2 regulate macrophage trafficking by induction of leukocyte adhesion to the microvascular endothelium after brain injury [63]. In our model, $24 \mathrm{~h}$ after HI, we observed a decrease in the plasma level of CCL2 and CCL3 with concomitant upregulation in CSF. This may reflect an early rapid response of the immature brain to the insult aimed at recruiting cells to the injury site. Schilling et al. have demonstrated that CCL2-CCR2 axis differentially regulates hematogenous cell recruitment 


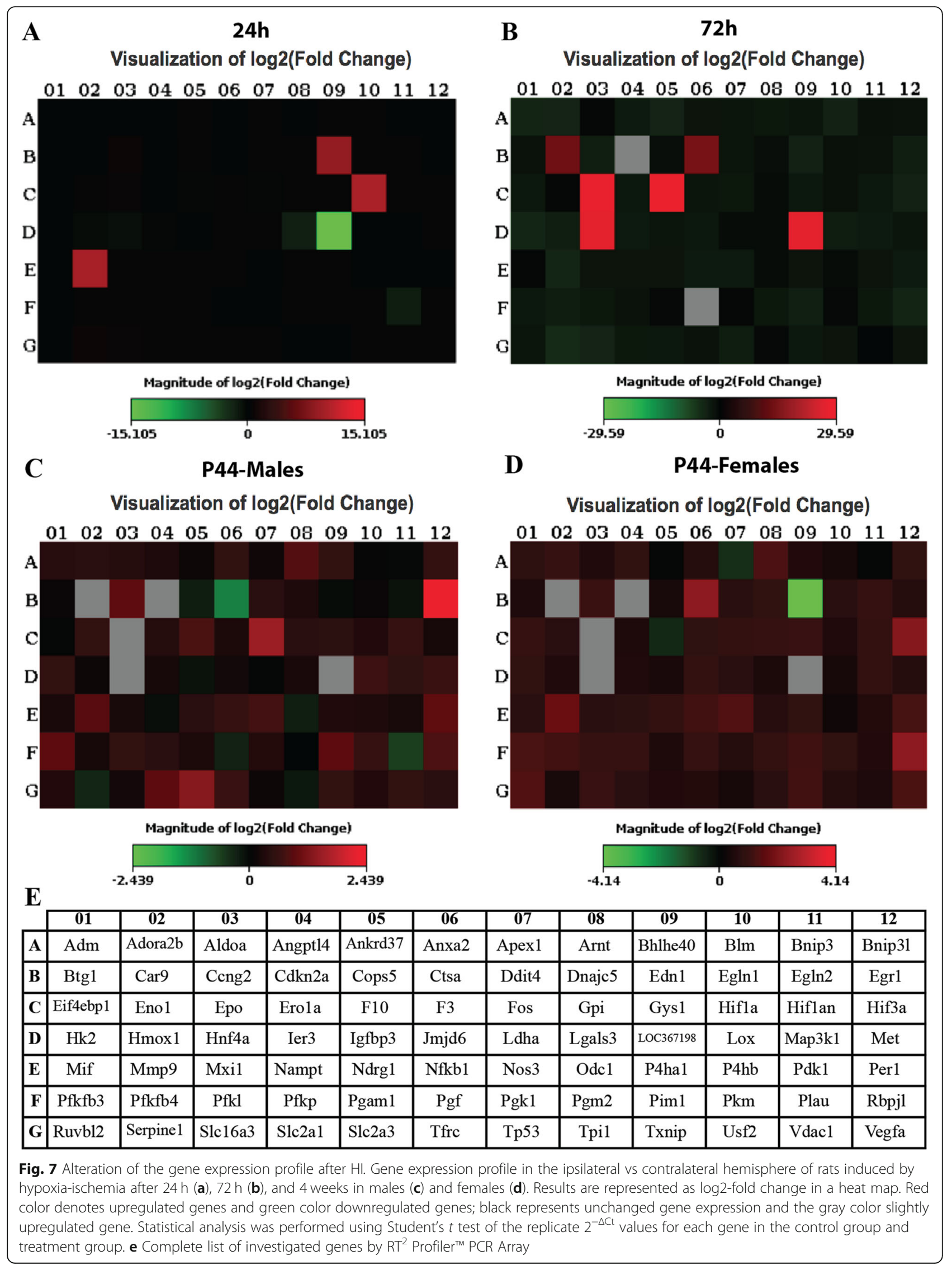


and sequential inhibition of selective CCL2-dependent pathways by CCR2 blockade may be an effective treatment to ameliorate tissue damage [63].

We also show that TNF- $\alpha$ was upregulated in CSF as soon as $24 \mathrm{~h}$ after $\mathrm{HI}$ till the end of the experiment while in plasma, it was upregulated only during the chronic phase. It has been demonstrated previously that TNF- $\alpha$ is mainly secreted by activated microglia and can activate death receptors, such as TRAIL, on neurons and oligodendroglia [64]. In addition, TNF- $\alpha$ can potentiate glutamate-mediated cytotoxicity by two mechanisms: indirectly, by inhibiting glutamate transport on astrocytes, and directly, by rapidly triggering the surface expression of $\mathrm{Ca}(+2)$ permeable AMPA receptors and NMDA receptors, while decreasing inhibitory GABAA receptors on neurons [65]. Thus, TNF- $\alpha$ may contribute to the tissue damage and loss that was observed at sacrifice. Moreover, TNF- $\alpha$ plays a critical role in HI by inducing neutrophil infiltration, increasing the permeability of endotheliocyte and activating matrix metalloproteinases, which damage the blood-brain barrier (BBB) leading to swelling and degeneration of neurons and glial cells [23, 66]. Kaur et al. have demonstrated that the unmyelinated axons showed an upregulated expression of TNF-R1 coupled with the disruption of myelin basic protein immunopositive processes of oligodendrocytes in the periventricular white matter of $\mathrm{HI}$ neonatal rats suggesting that an overproduction of TNF- $\alpha$ may damage axons and delay their myelination [22, 67]. It has been shown that an increased level of TNF- $\alpha$ and INF- $\gamma$ in the blood plays a role in depression- and anxiety-like behaviors $[68,69]$ which may explain the significant results that we observed in the open-field task with $\mathrm{HI}$ rats comparing to sham.

We also observed an increase in CSF1 (macrophage colony-stimulating factor) in HI rats. In particular, CSF1 was significantly increased in the acute phase after $\mathrm{HI}$ insult, at $72 \mathrm{~h}$, in plasma and in CSF. We have previously suggested in EAE (experimental allergic encephalomyelitis), a rat model for multiple sclerosis, that the overexpression of CSF1 (macrophage colony-stimulating factor) in CSF aggravate the inflammatory process by propagating the proinflammatory signals to the nearby resting microglia and astrocytes through an increased production of proinflamamtory cytokines [70]. This possibility was also investigated on the HI rodent model and recent results suggest that amoeboid microglial cells derived from CSF1 promotes astrocytes to generate proinflammatory cytokines, which may be involved in axonal damage following $\mathrm{HI}$ insult [22, 67, 71-73]. According to our results, it could thus be speculated that CSF1 signaling plays an important role in the early phase of HI, by trigging microglial activation, subsequent induction of neuroinflammation, and axonal damage, and this could lead to short-term as well as long-lasting behavioral deficits after the injury. Therefore, following HI, a synchronized inflammatory response in the brain arises that makes a significant contribution to HI-induced neuronal death.

Notably, inflammatory biomarkers show a genderrelated difference at early and late stages in both plasma and CSF, as already described for TNF- $\alpha$ [74], possibly reflecting the well-known gender-dependent immune and inflammatory responses described in several human inflammatory diseases [75] and in preclinical settings [76-78]. Overall, our data indicated the plasma biomarkers and not just CSF, as soon as fully characterized, and might as well monitor ongoing brain pathology.

We finally explored mRNA expression level in the cerebral cortex for several $(N=80)$ genes involved in tissue response to hypoxia. In particular, we found that Edn1, Hif1- $\alpha$, and Mmp9 were strongly upregulated in the ipsilateral lesion-compared to the contralateral hemisphere in $\mathrm{HI}$ rats at $24 \mathrm{~h}$ post-injury. It is known that endothelin-1 (ET-1) is a peptide hormone, encoded by Edn1 gene, with potent vasoconstrictor properties and is commonly involved in ischemia/hypoxia-associated microvascular endothelium [38, 79, 80]. Indeed, ET-1 peptide and mRNA levels are upregulated upon HI insult in mice [81]. Tsang et al. also found that ET-1 mRNA levels in the astrocyte-like cells and vascular endothelial cells are dynamically regulated by ischemia and may participate in perinatal ischemia-related neural damage [82].

ET-1 as a drug efficacy biomarker is well illustrated by the pre-clinical studies supporting the use of vasopressin in neonatal revitalization. This treatment has a neuroprotective potential as several studies demonstrated that vasopressin activates hippocampal interneurons, silencing synchronous neuronal activity [83]. This could reduce neuronal energy demand, which might have a neuroprotection outcome. Therefore, the detection of ET-1 as an inflammatory biomarker not only for early diagnoses but also for monitoring treatment efficacy and as prognostic for recovery and long-term disabilities could have beneficial outcomes.

Edn1 is regulated by Hif1- $\alpha[84,85]$ and the lack of this anti-survival factor in Hif1- $\alpha$ deficient mice might protect from early acute neuronal cell death and neurological impairment in the very acute phase after ischemic stroke [86]. It is also known that Hif- $1 \alpha$ upregulation mediates BBB damage in acute cerebral ischemia [8789]. The matrix metallopeptidase 9 (MMP9), when activated upon both cerebral ischemia and inflammation, can degrade collagen type IV in the endothelial basement membrane, leading to disruption of the BBB and allowing entry of peripheral immune cells into the brain [21, 79, 90-94]. Taking together, our results suggest that 
the response to $\mathrm{HI}$ injury occurs as soon as $24 \mathrm{~h}$ postinjury with an increase in Edn1, Hif1- $\alpha$, and Mmp9, which may affect the cerebral blood fluid flow, the BBB properties, and the infiltration of the peripheral immune cells into the brain. At $72 \mathrm{~h}$ post-HI injury, we found that Car9, Epo, Hnf4a, F10, and Cdkn2a mRNA levels were highly upregulated in the ipsilateral vs the contralateral hemisphere, suggesting the rapid follow-up of the nervous system of the injury occurred at $24 \mathrm{~h}$ and the attempt to recover. Those genes are involved in the clotting and hematopoietic processes, such as factor X (F10) gene that code for coagulation factors $[95,96]$ and Epo gene that has been known to stimulate the erythropoiesis in response to cellular hypoxia [97-99]. Interestingly, EPO is known to promote neurorestoration upon $\mathrm{HI}$ insults, and thus, the delayed EPO upregulation observed in this study could reflect a recovery attempt of the brain. EPO is an endogenous protein, synthesized in the fetal liver that has an impact on multiple critical pathways and influences the body's immune response [100]. EPO and EPO receptor are upregulated following $\mathrm{HI}$ injury and EPO has an anti-oxidant [101] as well as an anti-inflammatory [102] effect. It reduced apoptotic and excitotoxic cell injury [103-105]. Clinical trials evaluating EPO in infants with HI have shown to be promising; since hypothermia has become a standard of care therapy for HI, larger trials are currently ongoing evaluating EPO as a complement to cooling therapy results $[106,107]$.

During the chronic phase, i.e., 4 weeks after the HI injury, most of the genes were still upregulated in the ipsilateral vs contralateral hemisphere in both male and female rats. These findings might suggest that despite the attempt of recovery in the acute phase, as discussed earlier, the consequences of the early activation of the inflammatory cascade lead to extensive brain hemisphere atrophy which explains long-lasting behavioral deficits. Comparing to females, male $\mathrm{HI}$ rats have increased the mRNA level of Erg-1 (nerve growth factor-induced protein A). It has been shown that chemokine, adhesion receptor, procoagulant, and permeability-related genes are coordinately upregulated by rapid ischemia-mediated activation of Egr-1 [108, 109]. This might correlate with the impaired long-term memory observed in our model at the chronic phase. Indeed, Erg-1 has a critical role in the context of neuropsychiatric disorders due to its involvement in critical processes underlying neuronal activity, from neurotransmission and synaptic plasticity, to higher-order processes such as learning and memory, response to emotional stress and reward [110]. Jones et al. also showed that Egr-1 knockout mice have impaired spatial long-term memory while the short-term spatial memory is intact, suggesting a critical role for EGR1 in memory consolidation [111].

Ctsa (cathapsin A) mRNA level was downregulated in $\mathrm{HI}$ male at the chronic phase which might correlate with the decline in cognitive functions as well as in learning and memory observed in $\mathrm{HI}$ males comparing the females. A recent study showed that $\operatorname{Cath} A^{S 190 A}$ mice (mutant mouse with catalytically inactive cathapsin A enzyme) have learning impairments as well as long-term and spatial memory deficits compared with wild-type littermates, suggesting that Ctsa plays a significant role in learning and in memory consolidation [112].

While either sex of rats has been used for modeling hypoxia seizures [113], male rats are preferred in most studies to avoid potential bias due to sex differences [114]. Female rats show different developmental GABA profile during the critical period [115] and therefore respond differently to hypoxia-induced neonatal seizures. In our model, $\mathrm{HI}$ leads to an equivalent level of primary brain injury in males and in females during the acute phase ( 24 and $72 \mathrm{~h}$ after injury), no differences in the gene and protein expression. However, we observed a significant difference between male and female HI rats in the open field and the CatWalk tasks were males performed worse than females. Mirza et al. also previously reported this, where they showed that $\mathrm{HI}$ female mice have less behavioral deficits compared to males at the chronic stage of HI [116]. It is believed that $\mathrm{HI}$ is increasingly recognized as a sexually dimorphic disease where male infants suffer more long-term cognitive deficits compared with females with comparable brain damage $[74,116,117]$. In a more recent study done by Barkhuizen et al., where the long-term efficacy of multipotent adult progenitor cells was investigated, they found a persistent cognitive rescue in the female rats compared to the males. The gender differences they observed in the therapeutic responses are indicative of the clinical scenario where male infants have more mortality and morbidity after encephalopathy than females [118].

\section{Conclusion}

In conclusion, in our model of $\mathrm{HI}$ brain injury in juvenile rats, we have shown an early activation of the inflammatory cascade leading to increased production of several proinflammatory cytokines and chemokines such as TNF$\alpha$ and IL- 6 . These early responses could contribute to a cascade of events causing delayed cellular death and the subsequent tissue damage occurring in the hemisphere subjected to HI. This cascade of events, in turn, leads to the short-term as well as long-lasting neurobehavioral deficits, such as retarded development of motor coordination, observed in this study. Since cytokine, such as TNF- $\alpha$, production precedes and can contribute to brain damage, their significance as early biomarkers is relevant. A full characterization of the early neuroinflammatory responses could be of diagnostic and prognostic value and also for initiating and monitoring current and future therapeutic intervention aimed to neuroprotection. 


\section{Supplementary information}

Supplementary information accompanies this paper at https://doi.org/10. 1186/s12974-019-1595-0

Additional file 1: Figure S1. Timeline of the experimental procedure and behavioral tests performed after HI. HI was induced at P7 in both female and male Wistar pup rats (12-14 g weight). Two animal groups were sacrificed 24 and $72 \mathrm{~h}$ after injury. A third group was subject to behavioral tests: from P8 to P21 neurological reflex tests were performed. The same group was subject to the different long-term behavioral test (open field, Rota-rod, catwalk, and MWM) with one or 2 days off between the tests. At the end of the final test (MWM) rats were sacrificed for transcriptomic and proteomic analysis.

Additional file 2: Figure S2. Log2 fold change of gene expression in the ipsilateral vs contralateral hemisphere of rats induced by Hypoxia ischemia after $24 \mathrm{~h}$ (A) $72 \mathrm{~h}$ (B) 4 weeks in males (C) and females (D).

Additional file 3: Table S1. Raw data of plasma level of different cytokines, chemokines and growth factors in sham and HI rats at different time points. Results are presented as mean \pm SEM $(\mathrm{pg} / \mathrm{mL})$, with the $P$ value (one-way ANOVA and Tukey's multiple comparison test).

Additional file 4: Table S2. Raw data of CSF level of different cytokines, chemokines and growth factors in sham and $\mathrm{HI}$ rats at different time points. Results are presented as mean \pm SEM $(\mathrm{pg} / \mathrm{mL})$, with the $P$ value (one-way ANOVA and Tukey's multiple comparison test).

\section{Abbreviations}

BBB: Blood-brain barrier; CCA: Common carotid artery; CNS: Central nervous system; CSF: Cerebral spinal fluid; CT: Computed tomography;

EEG: Electroencephalogram; HI: Hypoxia-ischemia; MRI: Magnetic resonance imaging; MWM: Morris water maze

\section{Acknowledgements}

Not applicable.

\section{Authors' contributions}

All authors had full access to all the data in the study and take responsibility for the integrity of the data and the accuracy of the data analysis. NB, LL, and LG contributed to the study concept and design. NB, SS, AG, and MF contributed to the acquisition of the data. NB, SS, AG, and MF contributed to the analysis and interpretation of the data. NB, LL, MF, and FF contributed to the drafting of the manuscript and the critical revision of the article. All authors read and approved the final manuscript.

\section{Funding}

This work was supported by the European Union's Seventh Framework Program FP7 under Grant agreement 607962 (nEUROinflammation). The partial support of IRMI project (Italian Regenerative Medicine Infrastructure) was supported by the Italian Ministry of Education, University and Research (CTN01_00177_888744).

\section{Availability of data and materials}

The datasets used and analyzed during the current study are included within the article and its additional files. All material used in this manuscript will be made available to researchers subject to confidentiality.

\section{Ethics approval and consent to participate}

All experimental procedures were performed following the European Community Council Directives (86/609/EEC), approved by the intramural ethical committee for animal experimentation of Bologna University, and complied with the guidelines published in the NIH Guide for the Care and Use of Laboratory.

\section{Consent for publication}

Not applicable.

\section{Competing interests}

NB has received a Marie Curie fellowship under the European Union's Seventh Framework Program FP7 under Grant agreement 607962 (nEUROinflammation). The other authors declare no conflict of interest.

\section{Author details}

Corporate Pre-clinical R\&D, Chiesi Farmaceutici S.p.A, Largo Belloli 11/A, 43122 Parma, Italy. ${ }^{2}$ Health Science and Technologies Interdepartmental Center for Industrial Research, University of Bologna, Via Tolara di Sopra 41/E I-40064 Ozzano Emilia, BO, Italy. ${ }^{3}$ IRET Foundation, Via Tolara di Sopra 41/E, 40064 Ozzano Emilia, BO, Italy. ${ }^{4}$ Department of Veterinary Medical Sciences, University of Bologna, Via Tolara di Sopra 50, 40064 Ozzano Emilia, BO, Italy. ${ }^{5}$ Department of Pharmacy and Biotechnology, University of Bologna, Via Tolara di Sopra 41, 40064 Ozzano Emilia, BO, Italy.

Received: 17 June 2019 Accepted: 23 September 2019

Published online: 28 October 2019

\section{References}

1. Bhalala US, Koehler RC, Kannan S. Neuroinflammation and neuroimmune dysregulation after acute hypoxic-ischemic injury of developing brain. Front Pediatr. 2014;2:144.

2. Hagberg H, Mallard C, Ferriero DM, Vannucci SJ, Levison SW, Vexler ZS, et al. The role of inflammation in perinatal brain injury. Nat Rev Neurol. 2015;11: 192-208.

3. Kharoshankaya L, Stevenson NJ, Livingstone V, Murray DM, Murphy BP, Ahearne CE, et al. Seizure burden and neurodevelopmental outcome in neonates with hypoxic-ischemic encephalopathy. Dev Med Child Neurol. 2016:58:1242-8.

4. Kinney HC, Volpe JJ. Chapter 18 - Hypoxic-ischemic injury in the term infant: neuropathology. In: Volpe's Neurology Newborn Sixth Ed: Elsevier; 2018. p. 484-99. Available from: https://www.sciencedirect.com/science/article/pii/ B9780323428767000181. Cited 2018 Feb 16.

5. Laptook AR. Birth asphyxia and hypoxic-ischemic brain injury in the preterm infant. Clin Perinatol. 2016:43:529-45.

6. Vannucci SJ, Hagberg H. Hypoxia-ischemia in the immature brain. J Exp Biol. 2004;207:3149-54.

7. Vexler ZS, Ferriero DM. Molecular and biochemical mechanisms of perinatal brain injury. Semin Neonatol SN. 2001;6:99-108.

8. Acharya J, Rajamohan AG, Skalski MR, Law M, Kim P, Gibbs W. C angiography of the head in extracorporeal membrane oxygenation. AJNR Am J Neuroradiol. 2017:38:773-6.

9. Jan S, Northington FJ, Parkinson CM, Stafstrom CE. EEG monitoring technique influences the management of hypoxic-ischemic seizures in neonates undergoing therapeutic hypothermia. Dev Neurosci. 2017;39:82-8.

10. Lv H, Wang Q, Wu S, Yang L, Ren P, Yang Y, et al. Neonatal hypoxic ischemic encephalopathy-related biomarkers in serum and cerebrospinal fluid. Clin Chim Acta Int J Clin Chem. 2015;450:282-97.

11. Thoresen M, Hellström-Westas L, Liu X, de Vries LS. Effect of hypothermia on amplitude-integrated electroencephalogram in infants with asphyxia. Pediatrics. 2010;126:e131-9.

12. Thornton C, Rousset Cl, Kichev A, Miyakuni Y, Vontell R, Baburamani AA, et al. Molecular mechanisms of neonatal brain injury. Neurol Res Int. 2012; 2012:e506320.

13. Disdier C, Zhang J, Fukunaga Y, Lim Y-P, Qiu J, Santoso A, et al. Alterations in inter-alpha inhibitor protein expression after hypoxic-ischemic brain injury in neonatal rats. Int J Dev Neurosci Off J Int Soc Dev Neurosci. 2018; 65:54-60.

14. Lai JCY, Rocha-Ferreira E, Ek CJ, Wang X, Hagberg H, Mallard C. Immune responses in perinatal brain injury. Brain Behav Immun. 2017;63:210-23.

15. Saliba E, Henrot A. Inflammatory mediators and neonatal brain damage. Biol Neonate. 2001;79:224-7.

16. Thorngren-Jerneck K, Alling C, Herbst A, Amer-Wahlin I, Marsal K. S100 protein in serum as a prognostic marker for cerebral injury in term newborn infants with hypoxic ischemic encephalopathy. Pediatr Res. 2004;55:406-12.

17. McRae A, Gilland E, Bona E, Hagberg H. Microglia activation after neonatal hypoxic-ischemia. Dev Brain Res. 1995;84:245-52.

18. Sawada M, Suzumura A, Yamamoto H, Marunouchi T. Activation and proliferation of the isolated microglia by colony stimulating factor-1 and possible involvement of protein kinase C. Brain Res. 1990;509:119-24.

19. Hedtjärn M, Leverin A-L, Eriksson K, Blomgren K, Mallard C, Hagberg H. Interleukin-18 involvement in hypoxic-ischemic brain injury. J Neurosci. 2002;22:5910-9.

20. Doverhag C, Hedtjärn M, Poirier F, Mallard C, Hagberg H, Karlsson A, et al. Galectin-3 contributes to neonatal hypoxic-ischemic brain injury. Neurobiol Dis. 2010;38:36-46. 
21. Svedin P, Hagberg H, Sävman K, Zhu C, Mallard C. Matrix metalloproteinase9 gene knock-out protects the immature brain after cerebral hypoxiaischemia. J Neurosci. 2007;27:1511-8.

22. Kaur C, Rathnasamy G, Ling E-A. Roles of activated microglia in hypoxia induced neuroinflammation in the developing brain and the retina. J Neuroimmune Pharmacol Off J Soc Neurolmmune Pharmacol. 2013;8:66-78.

23. Liu F, McCullough LD. Inflammatory responses in hypoxic ischemic encephalopathy. Acta Pharmacol Sin. 2013;34:1121-30.

24. Riljak V, Kraf J, Daryanani A, Jiruška P, Otáhal J. Pathophysiology of perinatal hypoxic-ischemic encephalopathy - biomarkers, animal models and treatment perspectives. Physiol Res. 2016;65:S533-45.

25. Levine S. Anoxic-ischemic encephalopathy in rats. Am J Pathol. 1960;36:1-17.

26. Rice JE, Vannucci RC, Brierley JB. The influence of immaturity on hypoxicischemic brain damage in the rat. Ann Neurol. 1981;9:131-41.

27. Jensen FE, Applegate CD, Holtzman D, Belin TR, Burchfiel JL. Epileptogenic effect of hypoxia in the immature rodent brain. Ann Neurol. 1991;29:629-37.

28. Leonard AS, Hyder SN, Kolls BJ, Arehart E, KC WN, Veerapandiyan A, et al. Seizure predisposition after perinatal hypoxia: effects of subsequent age and of an epilepsy predisposing gene mutation. Epilepsia. 2013;54:1789-800.

29. Owens J, Robbins CA, Wenzel HJ, Schwartzkroin PA. Acute and chronic effects of hypoxia on the developing hippocampus. Ann Neurol. 1997;41:187-99.

30. Rakhade SN, Klein PM, Huynh T, Hilario-Gomez C, Kosaras B, Rotenberg A, et al. Development of later life spontaneous seizures in a rodent model of hypoxia-induced neonatal seizures. Epilepsia. 2011;52:753-65.

31. Hosono T, Kamo A, Hakotani S, Minato K, Akeno H, Taguchi Y, et al. Effect of hypothermia on motor function of adult rats after neonatal hyperthermic hypoxic-ischemic brain insult. Eur J Appl Physiol. 2010;109:35-9.

32. Mortola JP, Dotta A. Effects of hypoxia and ambient temperature on gaseous metabolism of newborn rats. Am J Phys. 1992;263:R267-72.

33. Rumajogee P, Bregman T, Miller SP, Yager JY, Fehlings MG. Rodent hypoxiaischemia models for cerebral palsy research: a systematic review. Front Neurol. 2016;7:57.

34. Balduini W, De Angelis V, Mazzoni E, Cimino M. Long-lasting behavioral alterations following a hypoxic/ischemic brain injury in neonatal rats. Brain Res. 2000;859:318-25.

35. Rojas JJ, Deniz BF, Miguel PM, Diaz R, Hermel Édo E-S, Achaval M, et al. Effects of daily environmental enrichment on behavior and dendritic spine density in hippocampus following neonatal hypoxia-ischemia in the rat. Exp Neurol. 2013;241:25-33.

36. Takao K, Tanda K, Nakamura K, Kasahara J, Nakao K, Katsuki M, et al. Comprehensive behavioral analysis of calcium/calmodulin-dependent protein kinase IV knockout mice. PLoS One. 2010;5:e9460.

37. Hattori T, Sato $Y$, Kondo T, Ichinohashi $Y$, Sugiyama $Y$, Yamamoto M, et al. Administration of umbilical cord blood cells transiently decreased hypoxicischemic brain injury in neonatal rats. Dev Neurosci. 2015;37:95-104.

38. Chou I-C, Trakht T, Signori C, Smith J, Felt BT, Vazquez DM, et al. Behavioral/ environmental intervention improves learning after cerebral hypoxiaischemia in rats. Stroke. 2001;32:2192-7.

39. Liu L, Duff K. A technique for serial collection of cerebrospinal fluid from the cisterna magna in mouse. J Vis Exp JoVE. 2008;21:960-21.

40. Rodríguez-Fanjul J, Fernández-Feijóo CD, Camprubí MC. A new technique for collection of cerebrospinal fluid in rat pups. J Exp Neurosci. 2015;9:37-41.

41. Daskalopoulos EP, Hermans KCM, van Delft L, Altara R, Blankesteijn WM. Inflammation in Heart Failure, first ed. Academic Press; 2014.

42. Houser B. Bio-Rad's Bio-Plex ${ }^{\oplus}$ suspension array system, xMAP technology overview. Arch Physiol Biochem. 2012;118:192-6.

43. Ten VS, Bradley-Moore M, Gingrich JA, Stark RI, Pinsky DJ. Brain injury and neurofunctional deficit in neonatal mice with hypoxic-ischemic encephalopathy. Behav Brain Res. 2003;145:209-19.

44. Wagner BP, Nedelcu J, Martin E. Delayed postischemic hypothermia improves long-term behavioral outcome after cerebral hypoxia-ischemia in neonatal rats. Pediatr Res. 2002;51:354-60.

45. Lubics A, Reglodi D, Tamás A, Kiss P, Szalai M, Szalontay L, et al. Neurological reflexes and early motor behavior in rats subjected to neonatal hypoxic-ischemic injury. Behav Brain Res. 2005;157:157-65.

46. Patel S, Player MR. Colony-stimulating factor-1 receptor inhibitors for the treatment of cancer and inflammatory disease. Curr Top Med Chem. 2009;9: 599-610.

47. Antier D, Zhang BL, Mailliet F, Akoka S, Pourcelot L, Sannajust F. Effects of neonatal focal cerebral hypoxia-ischemia on sleep-waking pattern, ECoG power spectra and locomotor activity in the adult rat. Brain Res. 1998;807:29-37.
48. de Paula S, Vitola AS, Greggio S, de Paula D, Mello PB, Lubianca JM, et al. Hemispheric brain injury and behavioral deficits induced by severe neonatal hypoxia-ischemia in rats are not attenuated by intravenous administration of human umbilical cord blood cells. Pediatr Res. 2009;65:631-5.

49. Goren B, Cakir A, Ocalan B, Serter Kocoglu S, Alkan T, Cansev M, et al. Longterm cognitive effects of uridine treatment in a neonatal rat model of hypoxic-ischemic encephalopathy. Brain Res. 2017;1659:81-7.

50. Johnston MV, Hagberg H. Sex and the pathogenesis of cerebral palsy. Dev Med Child Neurol. 2007;49:74-8.

51. Hagberg H, Wilson MA, Matsushita H, Zhu C, Lange M, Gustavsson M, et al. PARP-1 gene disruption in mice preferentially protects males from perinatal brain injury. J Neurochem. 2004;90:1068-75.

52. Barth TM, Stanfield BB. The recovery of forelimb-placing behavior in rats with neonatal unilateral cortical damage involves the remaining hemisphere. J Neurosci. 1990;10:3449-59.

53. Alsina M, Martín-Ancel A, Alarcon-Allen A, Arca G, Gayá F, García-Alix A. The severity of hypoxic-ischemic encephalopathy correlates with multiple organ dysfunction in the hypothermia era. Pediatr Crit Care Med J Soc Crit Care Med World Fed Pediatr Intensive Crit Care Soc. 2017;18:234-40.

54. LaRosa DA, Ellery SJ, Walker DW, Dickinson H. Understanding the full spectrum of organ injury following intrapartum asphyxia. Front Pediatr. 2017; 5. Available from: https://www.ncbi.nlm.nih.gov/pmc/articles/ PMC5313537/. Cited 2019 May 7.

55. Hedtjärn M, Mallard C, Hagberg H. Inflammatory gene profiling in the developing mouse brain after hypoxia-ischemia. J Cereb Blood Flow Metab Off J Int Soc Cereb Blood Flow Metab. 2004;24:1333-51.

56. Moyer MW. New biomarkers sought for improving sepsis management and care. Nat Med. 2012;18:999.

57. Drews K, Szczapa J, Zak J, Andrzejewska R, Zak L, Mackiewicz A. Blood serum concentration of C-reactive protein and interleukin- 6 in diagnosis of neonatal infections. Ann N Y Acad Sci. 1995;762:398-9.

58. Lusyati S, Hulzebos CV, Zandvoort J, Sukandar H, Sauer PJJ. Cytokines patterns in newborn infants with late onset sepsis. J Neonatal-Perinat Med. 2013;6:153-63.

59. Martín-Ancel A, García-Alix A, Pascual-Salcedo D, Cabañas F, Valcarce M, Quero J. Interleukin-6 in the cerebrospinal fluid after perinatal asphyxia is related to early and late neurological manifestations. Pediatrics. 1997;100: 789-94.

60. Shahkar L, Keshtkar A, Mirfazeli A, Ahani A, Roshandel G. The role of IL-6 for predicting neonatal sepsis: a systematic review and meta-analysis. Iran J Pediatr. 2011;21:411-7.

61. Biber K, Boddeke E. Neuronal CC chemokines: the distinct roles of CCL21 and CCL2 in neuropathic pain. Front Cell Neurosci. 2014:8:210.

62. Dimitrijevic OB, Stamatovic SM, Keep RF, Andjelkovic AV. Absence of the chemokine receptor CCR2 protects against cerebral ischemia/reperfusion injury in mice. Stroke. 2007:38:1345-53.

63. Schilling M, Strecker J-K, Ringelstein EB, Schäbitz W-R, Kiefer R. The role of CC chemokine receptor 2 on microglia activation and blood-borne cell recruitment after transient focal cerebral ischemia in mice. Brain Res. 2009; 1289:79-84

64. Li S-J, Liu W, Wang J-L, Zhang Y, Zhao D-J, Wang T-J, et al. The role of TNF$a, I L-6, I L-10$, and GDNF in neuronal apoptosis in neonatal rat with hypoxicischemic encephalopathy. Eur Rev Med Pharmacol Sci. 2014;18:905-9.

65. Olmos G, Lladó J. Tumor necrosis factor alpha: a link between neuroinflammation and excitotoxicity. Mediat Inflamm. 2014;2014:861231.

66. Szaflarski J, Burtrum D, Silverstein FS. Cerebral hypoxia-ischemia stimulates cytokine gene expression in perinatal rats. Stroke. 1995;26:1093-100.

67. Deng YY, Lu J, Ling E-A, Kaur C. Microglia-derived macrophage colony stimulating factor promotes generation of proinflammatory cytokines by astrocytes in the periventricular white matter in the hypoxic neonatal brain. Brain Pathol Zurich Switz. 2010;20:909-25.

68. Firdaus F, Zafeer MF, Ahmad M, Afzal M. Anxiolytic and anti-inflammatory role of thymoquinone in arsenic-induced hippocampal toxicity in Wistar rats. Heliyon. 2018;4:e00650.

69. Rajabi M, Mohaddes G, Farajdokht F, Nayebi Rad S, Mesgari M, Babri S. Impact of loganin on pro-inflammatory cytokines and depression- and anxiety-like behaviors in male diabetic rats. Physiol Int. 2018;105:116-26.

70. Borjini N, Fernández M, Giardino L, Calzà L. Cytokine and chemokine alterations in tissue, CSF, and plasma in early presymptomatic phase of experimental allergic encephalomyelitis (EAE), in a rat model of multiple sclerosis. J Neuroinflammation. 2016;13:291. 
71. Denes A, Vidyasagar R, Feng J, Narvainen J, McColl BW, Kauppinen RA, et al. Proliferating resident microglia after focal cerebral ischaemia in mice. J Cereb Blood Flow Metab Off J Int Soc Cereb Blood Flow Metab. 2007;27: 1941-53.

72. Escamilla J, Schokrpur S, Liu C, Priceman SJ, Moughon D, Jiang Z, et al. CSF1 receptor targeting in prostate cancer reverses macrophage-mediated resistance to androgen blockade therapy. Cancer Res. 2015;75:950-62.

73. Sanchez-Niño MD, Sanz AB, Ortiz A. Chronicity following ischaemiareperfusion injury depends on tubular-macrophage crosstalk involving two tubular cell-derived CSF-1R activators: CSF-1 and IL-34. Nephrol Dial Transplant. 2016;31:1409-16.

74. Al Mamun A, Yu H, Romana S, Liu F. Inflammatory responses are sex specific in chronic hypoxic-ischemic encephalopathy. Cell Transplant. 2018;27:1328-39.

75. Ardalan M, Chumak T, Vexler Z, Mallard C. Sex-dependent effects of perinatal inflammation on the brain: implication for neuro-psychiatric disorders. Int J Mol Sci. 2019;20:2270.

76. Hoogland ICM, Houbolt C, van Westerloo DJ, van Gool WA, van de Beek D. Systemic inflammation and microglial activation: systematic review of animal experiments. J Neuroinflammation. 2015;12:114.

77. Massella A, D'Intino G, Fernández M, Sivilia S, Lorenzini L, Giatti S, et al. Gender effect on neurodegeneration and myelin markers in an animal model for multiple sclerosis. BMC Neurosci. 2012;13:12.

78. Caruso D, D'Intino G, Giatti S, Maschi O, Pesaresi M, Calabrese D, et al. Sexdimorphic changes in neuroactive steroid levels after chronic experimenta autoimmune encephalomyelitis. J Neurochem. 2010;114:921-32.

79. Lee WLA, Michael-Titus AT, Shah DK. Hypoxic-ischaemic encephalopathy and the blood-brain barrier in neonates. Dev Neurosci. 2017;39:49-58,

80. Rajendran P, Rengarajan T, Thangavel J, Nishigaki Y, Sakthisekaran D, Sethi $\mathrm{G}$, et al. The vascular endothelium and human diseases. Int J Biol Sci. 2013;9: 1057-69.

81. Ho MCY, Lo ACY, Kurihara H, Yu ACH, Chung SSM, Chung SK. Endothelin-1 protects astrocytes from hypoxic/ischemic injury. FASEB J. 2001;15:618-26.

82. Tsang MC, Lo AC, Cheung PT, Chung SS, Chung SK. Perinatal hypoxia-/ ischemia-induced endothelin-1 mRNA in astrocyte-like and endothelial cells. Neuroreport. 2001;12:2265-70.

83. Spoljaric A, Seja P, Spoljaric I, Virtanen MA, Lindfors J, Uvarov P, et al. Vasopressin excites interneurons to suppress hippocampal network activity across a broad span of brain maturity at birth. Proc Natl Acad Sci U S A. 2017;114:E10819-28.

84. Hu J, Discher DJ, Bishopric NH, Webster KA. Hypoxia regulates expression of the endothelin-1 gene through a proximal hypoxia-inducible factor-1 binding site on the antisense strand. Biochem Biophys Res Commun. 1998; 245:894-9.

85. Semenza GL. Hypoxia-inducible factor 1: oxygen homeostasis and disease pathophysiology. Trends Mol Med. 2001;7:345-50.

86. Barteczek P, Li L, Ernst A-S, Böhler L-I, Marti HH, Kunze R. Neuronal HIF-1a and HIF-2a deficiency improves neuronal survival and sensorimotor function in the early acute phase after ischemic stroke. J Cereb Blood Flow Metab. 2017:37:291-306.

87. Cao Y, Li Z, Li H, Ni C, Li L, Yang N, et al. Hypoxia-inducible factor-1a is involved in isoflurane-induced blood-brain barrier disruption in aged rats model of POCD. Behav Brain Res. 2018;339:39-46.

88. Geng J, Wang L, Qu M, Song Y, Lin X, Chen Y, et al. Endothelial progenitor cells transplantation attenuated blood-brain barrier damage after ischemia in diabetic mice via HIF-1a. Stem Cell Res Ther. 2017:8:163.

89. Sun $Y$, Chen $X$, Zhang $X$, Shen $X$, Wang $M$, Wang $X$, et al. $\beta 2$-adrenergic receptor-mediated HIF-1a upregulation mediates blood brain barrier damage in acute cerebral ischemia. Front Mol Neurosci. 2017;10. Cited 2018 Feb 15. Available from. https://doi.org/10.3389/fnmol.2017.00257/full.

90. Bauer AT, Bürgers HF, Rabie T, Marti HH. Matrix metalloproteinase-9 mediates hypoxia-induced vascular leakage in the brain via tight junction rearrangement. J Cereb Blood Flow Metab Off J Int Soc Cereb Blood Flow Metab. 2010;30:837-48.

91. Higashida T, Kreipke CW, Rafols JA, Peng C, Schafer S, Schafer P, et al. The role of hypoxia-inducible factor-1a, aquaporin-4, and matrix metalloproteinase-9 in blood-brain barrier disruption and brain edema after traumatic brain injury. J Neurosurg. 2010;114:92-101.

92. Mun-Bryce S, Rosenberg GA. Gelatinase B modulates selective opening of the blood-brain barrier during inflammation. Am J Physiol-Regul Integr Comp Physiol. 1998;274:R1203-11.
93. Rosenberg GA, Dencoff JE, McGuire PG, Liotta LA, Stetler-Stevenson WG. Injury-induced 92-kilodalton gelatinase and urokinase expression in rat brain. Lab Investig J Tech Methods Pathol. 1994;71:417-22.

94. Ziemka-Nalecz M, Janowska J, Strojek L, Jaworska J, Zalewska T, FrontczakBaniewicz M, et al. Impact of neonatal hypoxia-ischaemia on oligodendrocyte survival, maturation and myelinating potential. J Cell Mol Med. 2018;22:207-22.

95. Hollborn M, Kohen L, Werschnik C, Tietz L, Wiedemann P, Bringmann A. Activated blood coagulation factor X ( $F X a)$ induces angiogenic growth factor expression in human retinal pigment epithelial cells. Invest Ophthalmol Vis Sci. 2012;53:5930-9.

96. Monteiro RQ, Lima LG, Gonçalves NP, De Souza MRA, Leal AC, Demasi MAA, et al. Hypoxia regulates the expression of tissue factor pathway signaling elements in a rat glioma model. Oncol Lett. 2016;12:315-22.

97. Jha NK, Jha SK, Sharma R, Kumar D, Ambasta RK, Kumar P. Hypoxia-induced signaling activation in neurodegenerative diseases: targets for new therapeutic strategies. J Alzheimers Dis. 2018;62:15-38.

98. Muller AJ, Marks JD. Hypoxic ischemic brain injury: potential therapeutic interventions for the future. NeoReviews. 2014;15:e177-86.

99. Suzuki N, Gradin K, Poellinger L, Yamamoto M. Regulation of hypoxiainducible gene expression after HIF activation. Exp Cell Res. 2017;356:182-6.

100. Wu YW, Gonzalez FF. Erythropoietin: a novel therapy for hypoxic-ischaemic encephalopathy? Dev Med Child Neurol. 2015;57(Suppl 3):34-9.

101. Maiese K, Chong ZZ, Hou J, Shang YC. Erythropoietin and oxidative stress. Curr Neurovasc Res. 2008:5:125-42

102. Sun Y, Calvert JW, Zhang JH. Neonatal hypoxia/ischemia is associated with decreased inflammatory mediators after erythropoietin administration. Stroke. 2005;36:1672-8.

103. Nair J, Kumar VHS. Current and emerging therapies in the management of hypoxic ischemic encephalopathy in neonates. Child Basel Switz. 2018:5:99.

104. Yiş U, Kurul SH, Kumral A, Tuğyan K, Cilaker S, Yilmaz O, et al. Effect of erythropoietin on oxygen-induced brain injury in the newborn rat. Neurosci Lett. 2008;448:245-9.

105. Juul SE, Beyer RP, Bammler TK, McPherson RJ, Wilkerson J, Farin FM. Microarray analysis of high-dose recombinant erythropoietin treatment of unilateral brain injury in neonatal mouse hippocampus. Pediatr Res. 2009;65:485-92.

106. Elmahdy H, El-Mashad A-R, El-Bahrawy H, El-Gohary T, El-Barbary A, Aly H. Human recombinant erythropoietin in asphyxia neonatorum: pilot trial. Pediatrics. 2010;125:e1135-42.

107. Zhu C, Kang W, Xu F, Cheng X, Zhang Z, Jia L, et al. Erythropoietin improved neurologic outcomes in newborns with hypoxic-ischemic encephalopathy. Pediatrics. 2009;124:e218-26.

108. Alagappan D, Balan M, Jiang Y, Cohen RB, Kotenko SV, Levison SW. Egr-1 is a critical regulator of EGF-receptor-mediated expansion of subventricular zone neural stem cells and progenitors during recovery from hypoxiahypoglycemia. ASN NEURO. 2013;5 Available from: https://www.ncbi.nlm. nih.gov/pmc/articles/PMC3786424/. Cited 2019 Apr 7.

109. Yan S-F, Fujita T, Lu J, Okada K, Shan Zou Y, Mackman N, et al. Egr-1, a master switch coordinating upregulation of divergent gene families underlying ischemic stress. Nat Med. 2000;6:1355-61.

110. Duclot $F$, Kabbaj M. The role of early growth response 1 (EGR1) in brain plasticity and neuropsychiatric disorders. Front Behav Neurosci. 2017;11 Available from: https://www.ncbi.nlm.nih.gov/pmc/articles/PMC5337695/. Cited 2019 Apr 7.

111. Jones MW, Errington ML, French PJ, Fine A, Bliss TV, Garel S, et al. A requirement for the immediate early gene Zif268 in the expression of late LTP and long-term memories. Nat Neurosci. 2001;4:289-96.

112. Calhan OY, Seyrantepe V. Mice with catalytically inactive cathepsin a display neurobehavioral alterations. Behav Neurol. 2017;2017 Available from: https:// www.ncbi.nlm.nih.gov/pmc/articles/PMC5241486/. Cited 2019 Apr 7.

113. Netto CA, Sanches E, Odorcyk FK, Duran-Carabali LE, Weis SN. Sexdependent consequences of neonatal brain hypoxia-ischemia in the rat. J Neurosci Res. 2017:95:409-21.

114. Charriaut-Marlangue C, Besson VC, Baud O. Sexually dimorphic outcomes after neonatal stroke and hypoxia-ischemia. Int J Mol Sci. 2017;19:1.

115. Galanopoulou AS. Dissociated gender-specific effects of recurrent seizures on GABA signaling in CA1 pyramidal neurons: role of GABAA receptors. J Neurosci. 2008:28:1557-67.

116. Mirza MA, Ritzel R, Xu Y, McCullough LD, Liu F. Sexually dimorphic outcomes and inflammatory responses in hypoxic-ischemic encephalopathy. J Neuroinflammation. 2015;12:32. 
117. Hill CA, Fitch RH. Sex differences in mechanisms and outcome of neonatal hypoxia-ischemia in rodent models: implications for sex-specific neuroprotection in clinical neonatal practice. Neurol Res Int. 2012;2012: 867531.

118. Barkhuizen $M$, van Mechelen $R$, Vermeer $M$, Chedraui $P$, Paes $D$, van den Hove DLA, et al. Systemic multipotent adult progenitor cells improve longterm neurodevelopmental outcomes after preterm hypoxic-ischemic encephalopathy. Behav Brain Res. 2019;362:77-81.

\section{Publisher's Note}

Springer Nature remains neutral with regard to jurisdictional claims in published maps and institutional affiliations.

Ready to submit your research? Choose BMC and benefit from:

- fast, convenient online submission

- thorough peer review by experienced researchers in your field

- rapid publication on acceptance

- support for research data, including large and complex data types

- gold Open Access which fosters wider collaboration and increased citations

- maximum visibility for your research: over $100 \mathrm{M}$ website views per year

At $\mathrm{BMC}$, research is always in progress.

Learn more biomedcentral.com/submissions 